Review

\title{
A Comprehensive Review of Additive Manufacturing (3D Printing): Processes, Applications and Future Potential
}

\author{
Santosh Kumar Parupelli and Salil Desai \\ Department of Industrial and Systems Engineering, North Carolina A\&T State University, Greensboro, USA
}

\author{
Article history \\ Received: 23-07-2019 \\ Revised: 20-09-2019 \\ Accepted: 09-10-2019 \\ Corresponding Author: \\ Salil Desai \\ Department of Industrial and \\ Systems Engineering, North \\ Carolina A\&T State University, \\ Greensboro, USA \\ Email: sdesai@ncat.edu
}

\begin{abstract}
Additive manufacturing (AM) also known as 3D printing is a technology that builds three-dimensional (3-D) solid objects. Customized 3D objects with complex geometries and integrated functional designs can be created using 3D printing. A comprehensive review of AM process with emphasis on recent advances achieved by various researchers and industries is discussed. Summary of each 3D printing technology capabilities, advantages and limitations is provided. This article reviews significant developments of 3D printing applications in different fields such as electronics, medical industry, aerospace, automobile, construction, fashion and food industry.
\end{abstract}

Keywords: 3D Printing, Additive Manufacturing, Applications, Innovation, Processes

\section{Introduction}

Additive Manufacturing (AM) also known as 3D printing builds three-Dimensional (3-D) solid objects. The object is built layer-by-layer using different materials such as polymers, composites, ceramic and metallic pastes depending on the requirement using digital data from a computer. Rapid prototyping, the first staged AM was developed to rapidly build prototypes. Stereolithography (STL) was the first process that emerged in the late eighties. Eventually, as this technology expanded to manufacture the final products, it was termed as rapid manufacturing (Ghazy, 2012). AM is a creative technology which has the capability to revolutionize the global manufacturing industry. Siemens research group estimates that $3 \mathrm{D}$ printing will become $400 \%$ faster and $50 \%$ cheaper in the next five years (Siemens and Zistl, 2014). In 2012, USA established National Additive Manufacturing Innovation Institute (NAMII), now known as America Makes in Youngstown, Ohio with federal funding of $\$ 50$ million. It is led by National Center for Defense Manufacturing and Machining. The mission of this institute is to accelerate and innovate $\mathrm{AM}$ and 3D printing to increase USA's global manufacturing competitiveness (U.S. Department of Defense, Manufacturing Technologies Program, 2012).

Typically, any AM process includes a combination of the following eight steps:

1. Conceptualization and CAD model

2. Conversion to STL format

3. Transfer to AM equipment and manipulation of STL file

4. Machine setup
5. Build the part

6. Removal and cleanup of the built part

7. Post processing of the part

8. Application (Gibson et al., 2012)

$\mathrm{AM}$ has been given different names, which include; layered manufacturing, additive fabrication, 3D printing, additive techniques, digital manufacturing, additive processes, free form fabrication and additive layered manufacturing (Ghazy, 2012). According to ASTM, AM is the "process of joining materials to make objects from 3D model data usually layer-by-layer, as opposed to subtractive manufacturing technologies such as traditional manufacturing" (Standard, 2012). There are different types of additive manufacturing processes, which include; photo-polymerization process (Jacobs and Francis, 1992), extrusion based systems (Comb et al., 1994), powder bed fusion processes (Beaman et al., 1997), (Cormier et al., 2004), material jetting processes (Engstrom, 2012a), binder jetting processes (Engstrom, 2012a), beam deposition processes (Balla et al., 2008), sheet lamination processes (Feygin and Freeform, 1991) and direct write technologies (Pique and Chrisey, 2001). AM has a variety of benefits over the traditional and subtractive manufacturing methods. Some of the important benefits include high degree of design freedom, efficiency, complexity and flexibility, reduced assembly and predictable production, support for green manufacturing initiatives, precise physical replication (Grimm, n.d.), (Peter, 2012). Due to the rapid development of the technology, AM has widened its applications to many fields such as electronics, medical, aerospace, construction, medical industry, fashion, food industry, automotive, oceanography and research (Wimpenny et al., 
2016). Complex structures lightweight structures can be built using AM techniques. This article provides a comprehensive overview of the different additive manufacturing process and their application in different fields. The article consists of three sections. Section 1 provides the background of the additive manufacturing market and its advantages. Section 2 describes a detailed literature about all the additive manufacturing process with limitations and advantages are provided. Section 3 delineates recent advances in the applications of additive manufacturing in electronics, medical industry, construction, food industry, aerospace, fashion industry and automotive industry.

\section{Additive Manufacturing Processes}

The AM processes builds parts layer-by-layer from bottom-up using the digital data from the computer. AM consists of variety of processes categorized by different with their respective advantages and disadvantages (Gibson et al., 2012). The overview of different AM process and the materials are presented in Table 1.

Table 1: Overview of AM processes [(Gibson et al., 2012)]

\begin{tabular}{|c|c|c|c|c|}
\hline Process & Technology & Materials & $\begin{array}{l}\text { Minimum layer } \\
\text { resolution }\end{array}$ & $\begin{array}{l}\text { Max build volume (LxWxH- } \\
\mathrm{mm}^{3} \text { ) and Applications }\end{array}$ \\
\hline $\begin{array}{l}\text { Photo- } \\
\text { polymerization }\end{array}$ & $\begin{array}{l}\text { Stereolithography (SLA) } \\
\text { Digital Light Processing (DLP) } \\
\text { Continuous Liquid } \\
\text { Interface Production(CLIP) } \\
\text { Scan, Spin and } \\
\text { Selectively Photocure (3SP) }\end{array}$ & Photopolymers & $\begin{array}{l}50-100 \mu \mathrm{m} \\
25-150 \mu \mathrm{m} \\
50-100 \mu \mathrm{m} \\
25-100 \mu \mathrm{m}\end{array}$ & $\begin{array}{l}1500 \times 750 \times 550 \\
192 \times 120 \times 230 \\
190 \times 112 \times 325 \\
266 \times 175 \times 193 \\
\text { Rapid prototypes, tooling, end } \\
\text { user parts and mold patterns. }\end{array}$ \\
\hline Extrusion Based Systems & $\begin{array}{l}\text { Fused Deposition Modeling } \\
\text { (FDM) }\end{array}$ & $\begin{array}{l}\text { Thermoplastics } \\
\text { (PLA, ABS, HIPS, } \\
\text { Nylon, PC) }\end{array}$ & $10-100 \mu \mathrm{m}$ & $\begin{array}{l}1500 \times 1100 \times 1500 \\
\text { Spare parts, automotive, testing } \\
\text { tool designs and jigs }\end{array}$ \\
\hline Powder Bed Fusion & $\begin{array}{l}\text { Selective laser sintering (SLS) } \\
\text { Electron Beam Melting (EBM) } \\
\text { Selective laser melting (SLM) } \\
\text { Selective heat sintering (SHS) } \\
\text { And Direct metal laser sintering } \\
\text { (DMLS) }\end{array}$ & $\begin{array}{l}\text { Polymers, Metals } \\
\text { and Ceramic powder }\end{array}$ & $\begin{array}{l}80 \mu \mathrm{m} \\
70 \mu \mathrm{m} \\
20-50 \mu \mathrm{m} \\
100 \mu \mathrm{m} \\
20-40 \mu \mathrm{m}\end{array}$ & $\begin{array}{l}381 \times 330 \times 460 \\
6096 \times 1194 \times 1524 \\
300 \times 300 \times 300 \\
160 \times 140 \times 150 \\
250 \times 250 \times 325 \\
\text { Aerospace, automotive, dental, } \\
\text { rapid prototyping and jewelry }\end{array}$ \\
\hline Binder Jetting & 3D printing & $\begin{array}{l}\text { Polymers, Waxes, } \\
\text { Metals and Foundry } \\
\text { sand }\end{array}$ & $90 \mu \mathrm{m}$ & $\begin{array}{l}2200 \times 1200 \times 600 \\
\text { Prototypes, casting patterns } \\
\text { and molds }\end{array}$ \\
\hline $\begin{array}{l}\text { Directed Energy } \\
\text { Deposition }\end{array}$ & $\begin{array}{l}\text { Laser Engineering Net Shape } \\
\text { (LENS) }\end{array}$ & Metals & $50-100 \mu \mathrm{m}$ & $\begin{array}{l}1500 \times 1500 \times 2100 \\
\text { Aerospace, military, repair metal } \\
\text { objects and satellites }\end{array}$ \\
\hline $\begin{array}{l}\text { Sheet Lamination } \\
\text { Processes }\end{array}$ & $\begin{array}{l}\text { Laminated Object Manufacturing } \\
\text { (LOM) }\end{array}$ & $\begin{array}{l}\text { Metals, Paper, } \\
\text { Plastic film }\end{array}$ & $100 \mu \mathrm{m}$ & $\begin{array}{l}256 \times 169 \times 150 \\
\text { Prototypes, plastic parts and } \\
\text { end user parts }\end{array}$ \\
\hline $\begin{array}{l}\text { Hybrid and Direct } \\
\text { Write AM }\end{array}$ & $\begin{array}{l}\text { Combination of microextrusion, } \\
\text { droplet based, laser and UV } \\
\text { curing, CNC machinining, etc. }\end{array}$ & $\begin{array}{l}\text { Ceramic materials } \\
\text { and Metal alloy }\end{array}$ & $50 \mu \mathrm{m}$ & $\begin{array}{l}734 \times 650 \times 559 \\
\text { Structural components and } \\
\text { embedded } 3 D \text { structures, }\end{array}$ \\
\hline
\end{tabular}

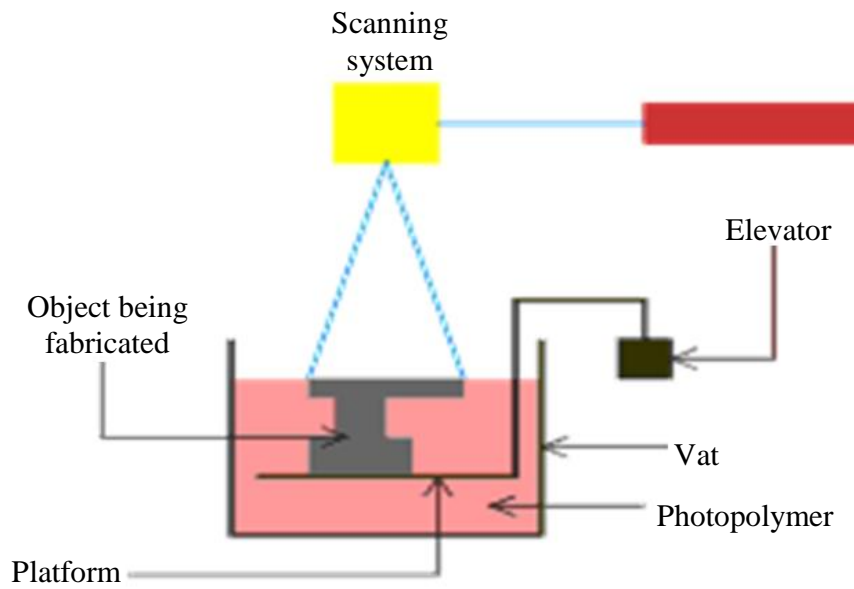

Fig. 1: SLA process (Ltd, 2015) Copyrights (C) ICM 2011] 


\section{Photopolymerization Process}

Photo-polymerization is an AM process which constructs 3D objects using a liquid polymer resin. This process is used to produce prototypes, models and patterns by curing a photopolymer resin with a UV laser (Jacobs and Francis, 1992). Schematic of SLA process is shown in Fig. 1.

The materials used in this process are different grades of polymers. Stereolithography (SLA) is the commonly used technology in this process. SLA was developed in 1986 by Charles Hull. Some of the structures in this process may need a support network to avoid the deformation of the object. These supports are built with the same material of the part and can be removed using sharp tools. The completed part is washed in a chemical bath to remove the excess resin and cured in UV oven.

SLA entails high level of accuracy and smooth surface finish of the parts. The drawbacks of this process are: It requires support structures, post-processing and postcuring steps (Jacobs and Francis, 1992). The applications of SLA are found in many industries including electronics, medical, aerospace, tooling master patters for injection molding, defense and form-fit studies ("Stereolithography (SL) Prototype Applications," n.d.).

\section{Extrusion-Based Systems}

Extrusion based systems are used for the production of plastic prototypes and low volume functional parts. The most commonly used extrusion-based technology is Fused Deposition Modeling (FDM). FDM is an extrusion-based system used for prototyping, modeling and production applications, was developed in the late 1980s by S. Scott Crump (Gibson et al., 2012). This process uses two types of materials namely, modeling material for the finished object and a support material for the temporary support material. The materials used in this process are ABS, PLA, PS, PC, PEI, ULTEM and Nylon (Comb et al., 1994). The FDM process is shown in Fig. 2.

The completed part is separated from the build platform and is washed in a chemical bath to remove the support material. FDM is a relatively cheap AM process compared to other AM processes and is simple to use. On the other hand, FDM is a slow process compared to other AM processes and has limited layer thickness accuracy. Applications of FDM are found in variety of industries; aerospace, automotive, medical, architecture, jewelry and art (Comb et al., 1994).

\section{Powder Bed Fusion Processes}

The powder bed fusion process uses either a laser, thermal energy or an electron beam as the energy source to melt and fuse small particles of powder to build 3D objects. This process uses broad range of material like, polymers, metals, ceramics and composites (Ghazy, 2012), (Gibson et al., 2012). Schematic of SLS process is shown in Fig 3. Selective laser sintering (SLS), electron beam melting (EBM), selective laser melting (SLM), selective heat sintering (SHS) and direct metal laser sintering (DMLS) are different types of techniques used in this process (Cormier et al., 2004), (Engstrom, 2012b). SLS was developed in the mid-1980s by Dr.

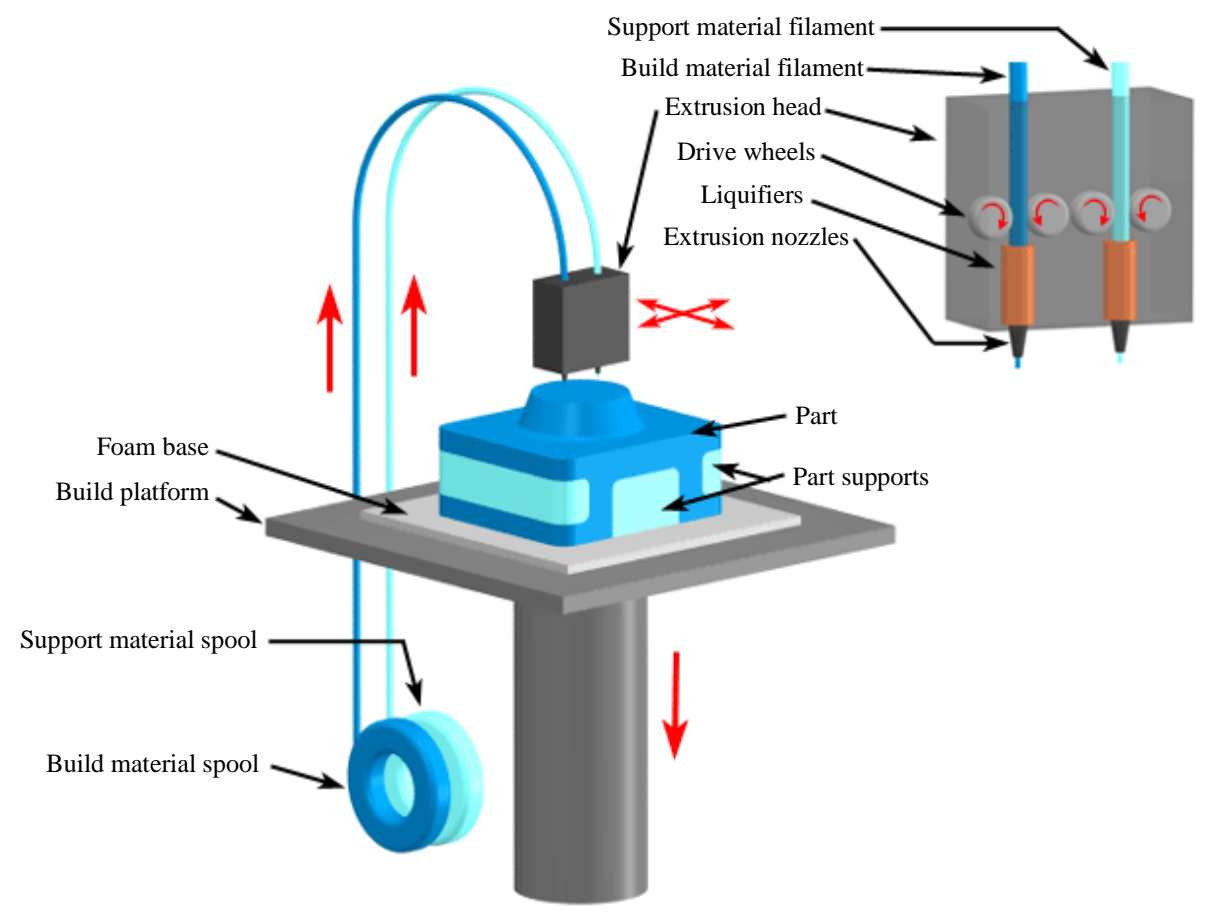

Fig. 2: FDM process [(“Fused Deposition Modeling (FDM),” 2008) Copyright C 2019 CustomPartNet] 


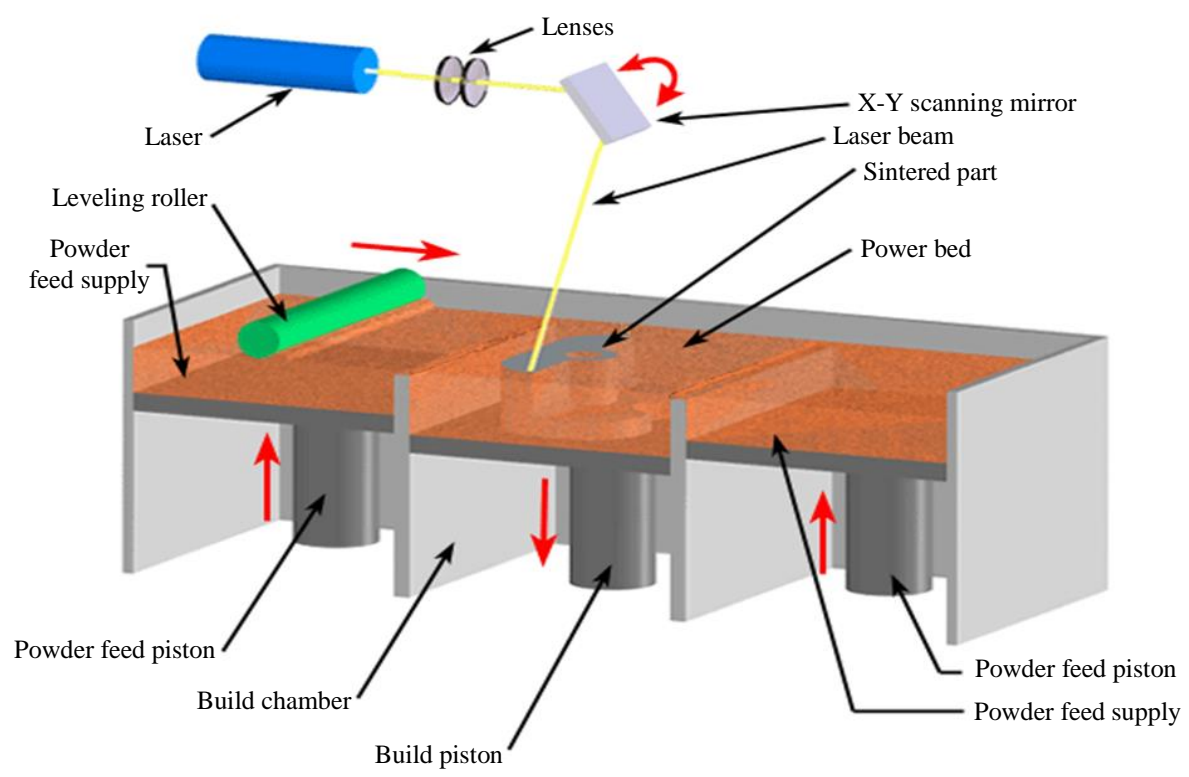

Fig. 3: SLS process [(“Rapid Prototyping,” 2008) Copyright (C) 2019 CustomPartNet]

Carl Deckard and Dr. Joe Beaman. In this process, a 3D model is formed by binding tiny particles of ceramic, glass and plastic together by heat from a laser source (Beaman et al., 1997). In PBF processes, support is not required while printing the overhang and unsupported structures as the left-over powder itself provides the necessary support. The finished parts tend to be porous and rough depending on the material used. Applications of PBF processes are found in variety of industries such as aerospace, automotive, medical, electronics and military (Gibson et al., 2012).

\section{Material Jetting Process}

Material jetting process uses inkjet print heads to dispense droplets of material on to the build platform layer-by-layer to build the 3D object. These processes use inkjet and other printing techniques to produce 3D structures (Engstrom, 2012a). Multiple arrays of printheads can be used to print an object with different materials. Support structures are built for the objects with complex geometries consisting of overhanging structures. These supports can be taken-off by immersing the object in a water-based liquid. Polymers are commonly used materials in this process due to their viscous nature (Gibson et al., 2012). Schematic of material jetting process is shown in Fig. 4 .

Parts with high accuracy, fine finishing and multiple colors can be produced. But the material properties are not as good as the SLA process. Applications of this process are found in prototypes for form and fit testing, rapid tooling patterns, medical devices and jewelry (“Jetted Photopolymer," 2008).

\section{Binder Jetting Process}

Binder jetting is an AM process which uses two materials; a powder material and a liquid binder to produce a 3D structure. This process has the ability to build parts of any geometry using a variety of materials such as metals, composites, ceramics, sand and polymers. 3D Printing (3DP) is a binder jetting process invented at the Massachusetts Institute of Technology in 1993 (Gibson et al., 2012). Schematic of binder jetting process is shown in Fig. 5. The remaining unbound powder acts as a support structure for the object. This process has the ability to print objects with solid layers and is cost-effective compared to other AM processes. On the other hand, object created using this process are fragile with limited mechanical properties. Applications of this process are found in prototypes, casting patterns, architecture and consumer goods (Engstrom, 2012a).

\section{Directed Energy Deposition}

Directed energy deposition is an AM process that deposits powder and fuses it simultaneously with a laser, electron beam or plasma arc to produce a part. Schematic of the directed energy deposition is shown in Fig. 6. This process is used to build a metal structure, repair or add additional features to the existing component. Variety of metals such as tool steel, stainless steel, titanium, nickel, cobalt alloys are used. Laser Engineering Net Shaping (LENS) is one of the techniques used in this AM process. LENS was developed at Sandia National Laboratories. This process is developed to produce metal parts with complex geometries from the CAD data by 
using metal powder and high-power laser beam (Ghazy, 2012), (Gibson et al., 2012). In this process, a multi axis nozzle is used to build the parts. The whole process is carried out in a vacuum or inert atmosphere.

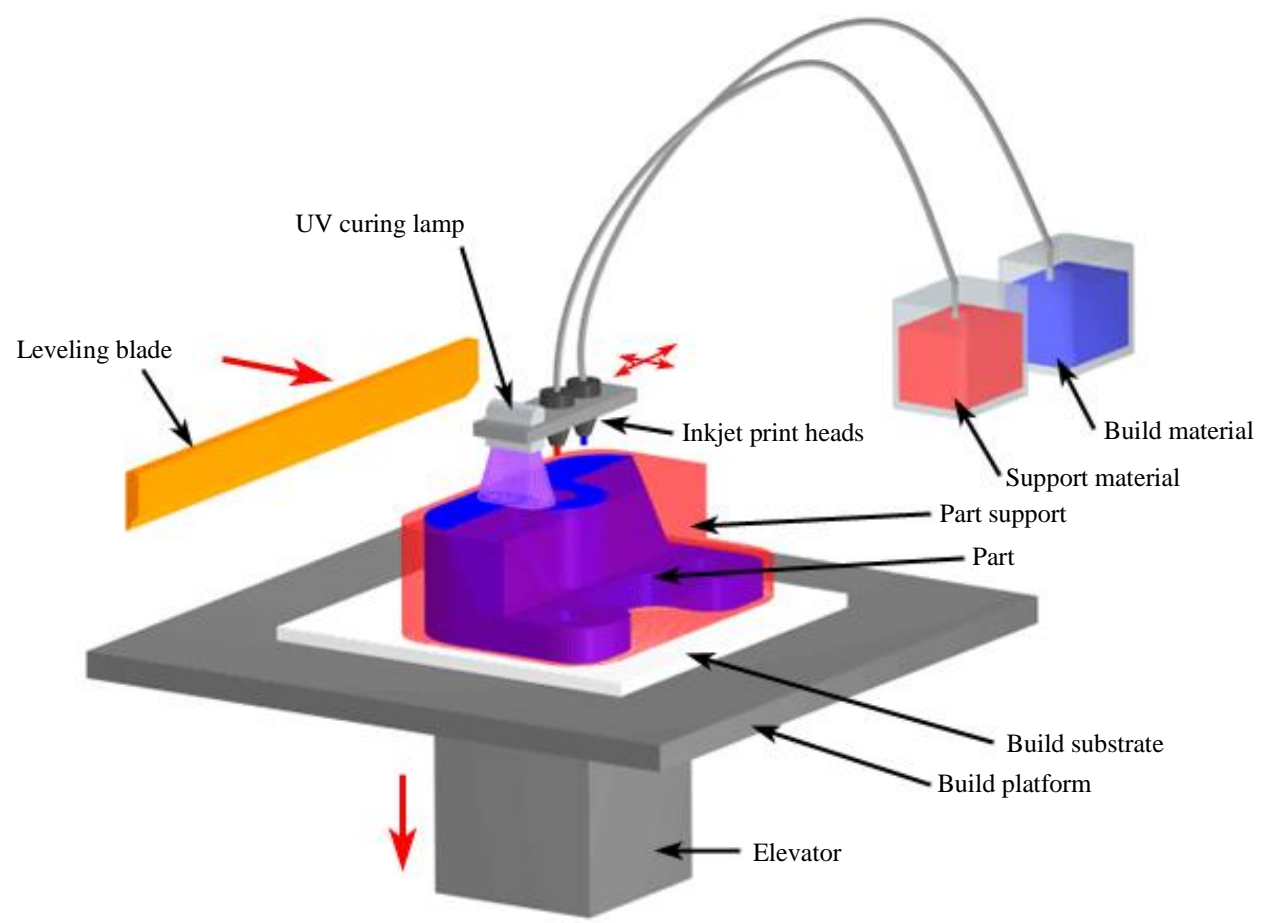

Fig. 4: Material jetting process [(“Jetted Photopolymer,” 2008) Copyright $\odot 2019$ CustomPartNet]

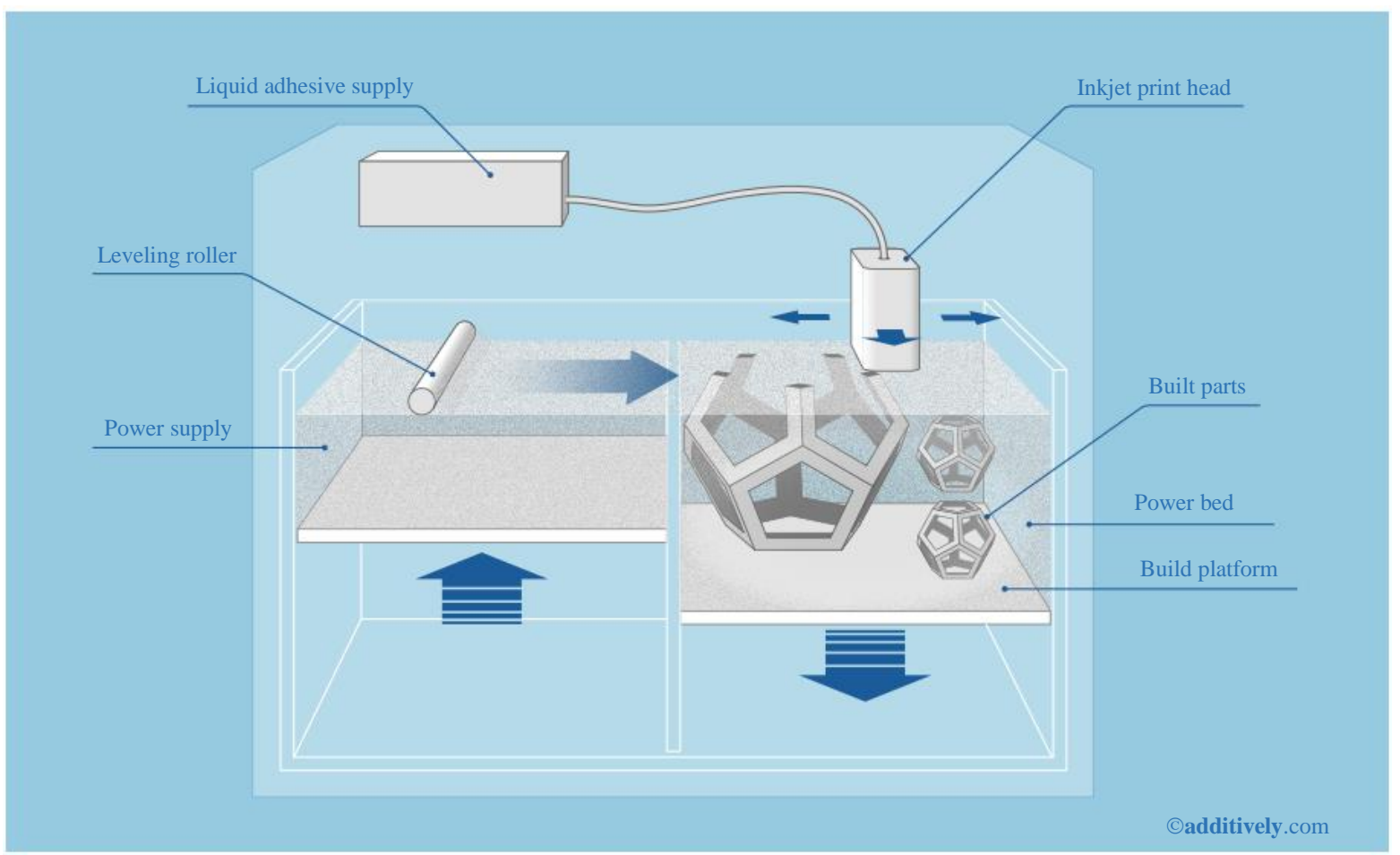

Fig. 5: Binder Jetting [(“Overview over 3D printing technologies: Binder Jetting,” n.d.) Copyright $\subset 2019$ additively.com] 
The advantage of this process is that it can produce fully dense objects with highly controllable microstructural features. On the other hand, the disadvantages are that the accuracy and surface finish of the parts is not as good as the PBF processes. And the process is limited to only metal powder. Applications of this process include; prototypes, aerospace components and medical implants (Gibson et al., 2012).

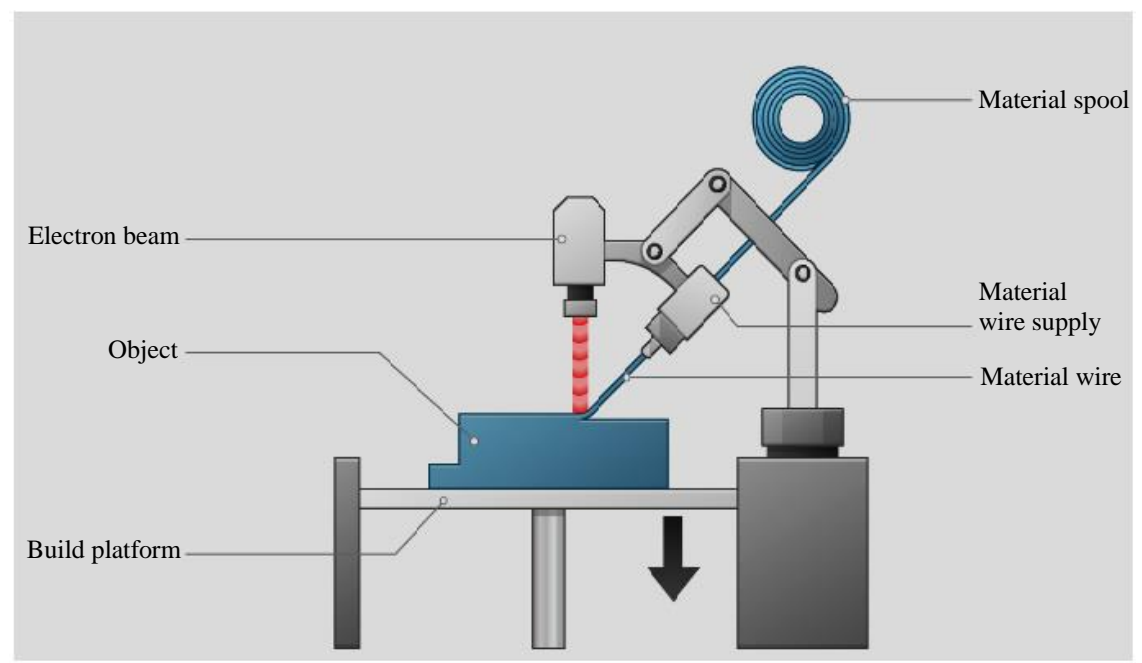

Fig. 6: Directed energy deposition [(3DExperience, 2018) Copyright @ 2018 3DExperience]

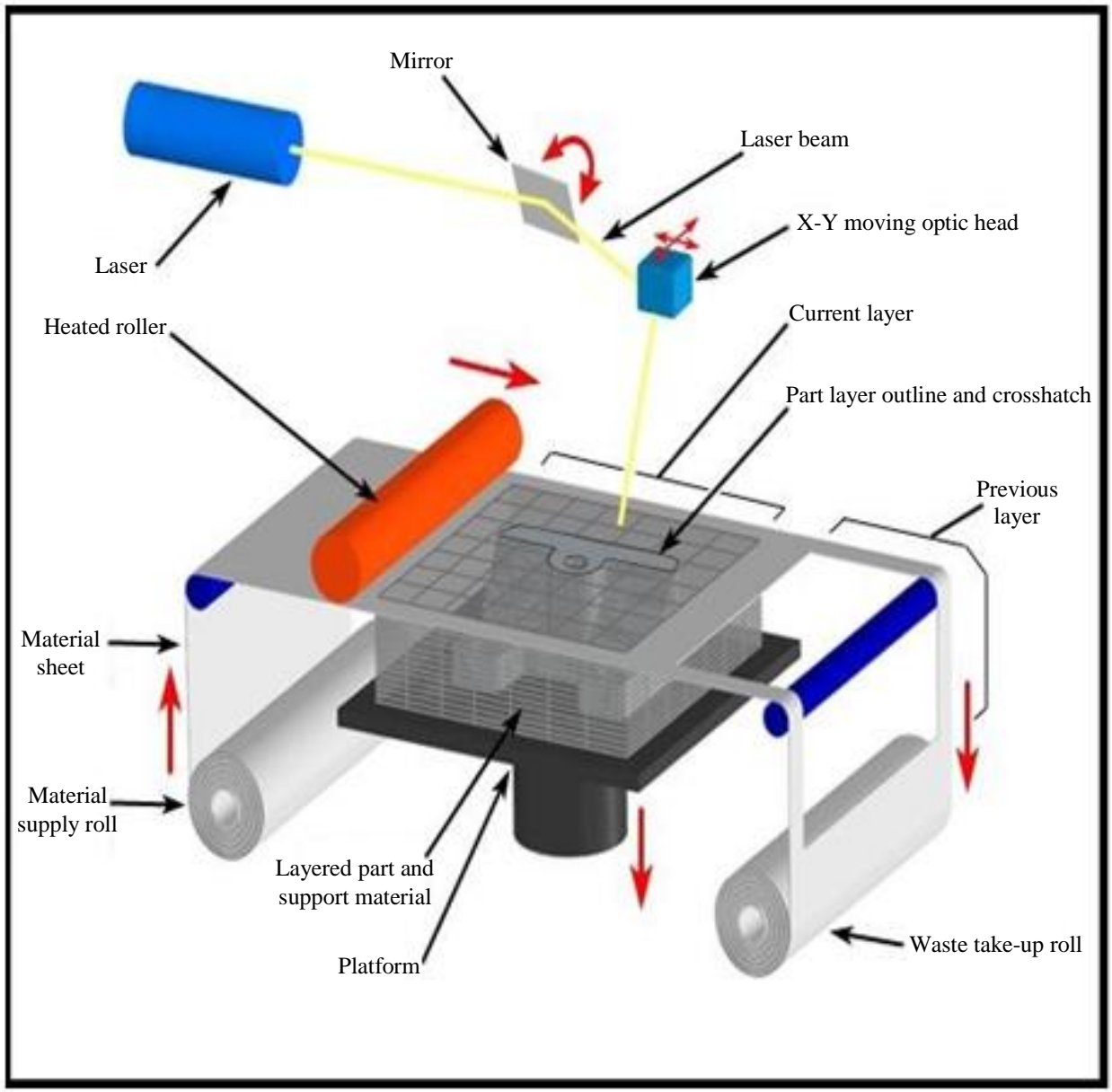

Fig. 7: LOM process [(“Laminated Object Manufacturing,” 2008) Copyright $(\underset{2019}{ } 2$ CustomPartNet] 


\section{Sheet Lamination Processes}

Sheet lamination is an AM process in which objects are produced by bonding sheets of material together. Materials used in this process are paper, plastic and metals. Different mechanisms such as adhesive bonding, thermal bonding, ultrasonic welding and clamping are used to bind the sheets together. Laminated Object Manufacturing (LOM) and Ultrasonic Additive Manufacturing (UAM) are the two main techniques in this process. LOM was developed by Helisys Inc. In LOM, a plastic material is laminated layer-by-layer using heat and pressure and then cut into required shape with a laser source (Feygin and Freeform, 1991). In UAM metal sheets are laminated layer-by-layer using ultrasonic welding and require additional $\mathrm{CNC}$ machining during the welding process (Ghazy, 2012), (Gibson et al., 2012). Schematic of the LOM process is shown in Fig. 7. The advantages compared to other AM process are that sheet lamination is fast and cost effective. Large objects can be produced as there is no chemical reaction involved. Disadvantages are that the accuracy of the parts are not as good as SLS process and the finish of the object varies on the material used. Applications of LOM are found in wide variety of industries (Gibson et al., 2012).

\section{Hybrid and Direct-Write (DW) Additive Manufacturing (AM) Process}

\section{Hybrid Process}

Hybrid manufacturing process can be defined as the combination of two or more manufacturing process for producing a part with a required accuracy and specifications. Depending upon the materials, equipment and process used the definition of the hybrid AM process varies (Manogharan et al., 2015). The International Academy for Production Engineering- CIRP defines hybrid process as follows (Zhu et al., 2013), (Manogharan, 2014):

1. Open definition: A hybrid manufacturing process combines two or more established manufacturing processes into a new combined set-up whereby the advantages of each discrete process can be exploited synergistically

2. Narrow definition: Hybrid processes comprise a simultaneous acting of different processing principles on the same processing zone

In some situations, multiple $\mathrm{AM}$ techniques are integrated within a single machine or subtractive techniques such as laser cladding or computer numerical control milling are combined with AM techniques to produce complex parts (Stucker, 2011). Current hybrid manufacturing systems use multi-axis systems for building the part features in any directions. Thus, it eliminates the need for building complex support structures. One of the advantages with these hybrid processes is that, functional parts for final use can be manufactured in a single setup (Siemens and Zistl, 2014). In the context of this research, hybrid process refers to the combination of DW techniques with other AM techniques. Generally, DW techniques are developed to fabricate multifunctional complex 3Dembedded electronic structures (Stucker, 2011).

\section{Direct-Write AM techniques}

Direct Write (DW) AM techniques are developed to build meso, micro and nano-scale 3D functional structures such as conductors, capacitors, insulators, batteries and sensors directly from a CAD file onto any surface without masks and tooling. DW techniques have the ability to deposit, dispense or process different types of materials over different surfaces in a preset pattern. DW techniques can transfer material and pattern processes at the same time (Pique and Chrisey, 2001). DW techniques are categorized into various types, such as laser transfer (Li et al., n.d.), micropen ${ }^{\mathrm{TM}}$ (Sun, 2010), MAPLE DW (Piqué et al., 2003), Laser CVD (Hiramatsu et al., 2007), Dip-pen (Piner et al., 1999), plasma spray (Ružić et al., 2012) and Ink-jet (Furlani, n.d.). There are many factors which differentiate these techniques, some of them include: Resolution, manufacturing flexibility, writing speed, pressure and temperature. Each technique has its own advantages and disadvantages. The Matrix assisted pulsed laser evaporation technique was developed for fabricating mesoscopic electronic devices with high precision by using metallic, resistive and dielectric materials (Piqué et al., 2003). A typical MAPLE DW system consists of laser, ribbon, substrate and camera as shown in Fig. 8. A laser transparent material is coated with a material of interest (ink) to form the ribbon. A pulsed laser is induced through the ribbon to eject the material onto the substrate. By allowing the laser to interact with the substrate directly micromachining of channels is possible. Material transfer and micromachining can be controlled by the computer. This technique has the ability to generate high-quality organic, biomaterial and polymer films on different types of substrate (Riggs et al., 2011).

Micropen $^{\mathrm{TM}}$ is a solid free form technique employed for fabricating a variety of electronic components. With Micropen DW approach highly integrated, multilayer components can be fabricated layer-by-layer by depositing slurries or liquid fluid in precise patterns using CAD data. This technique has the ability to deposit patterns on planar and 
curvilinear substrates (Pique and Chrisey, 2001). Micro pen makes use of variety of nozzle sizes ranging from 2 to 100 mils to pattern different print geometries. The resolution of the Micro pen ${ }^{\mathrm{TM}}$ depends on pen tip sizes, writing parameters and material rheology. Applications include: Fabrication of resistors, capacitors, RC filters, transformers, inductors and chemical sensors (Micropen ${ }^{T M}$ manual, n.d.). Schematic of Micro pen DW system is illustrated in Fig. 9.

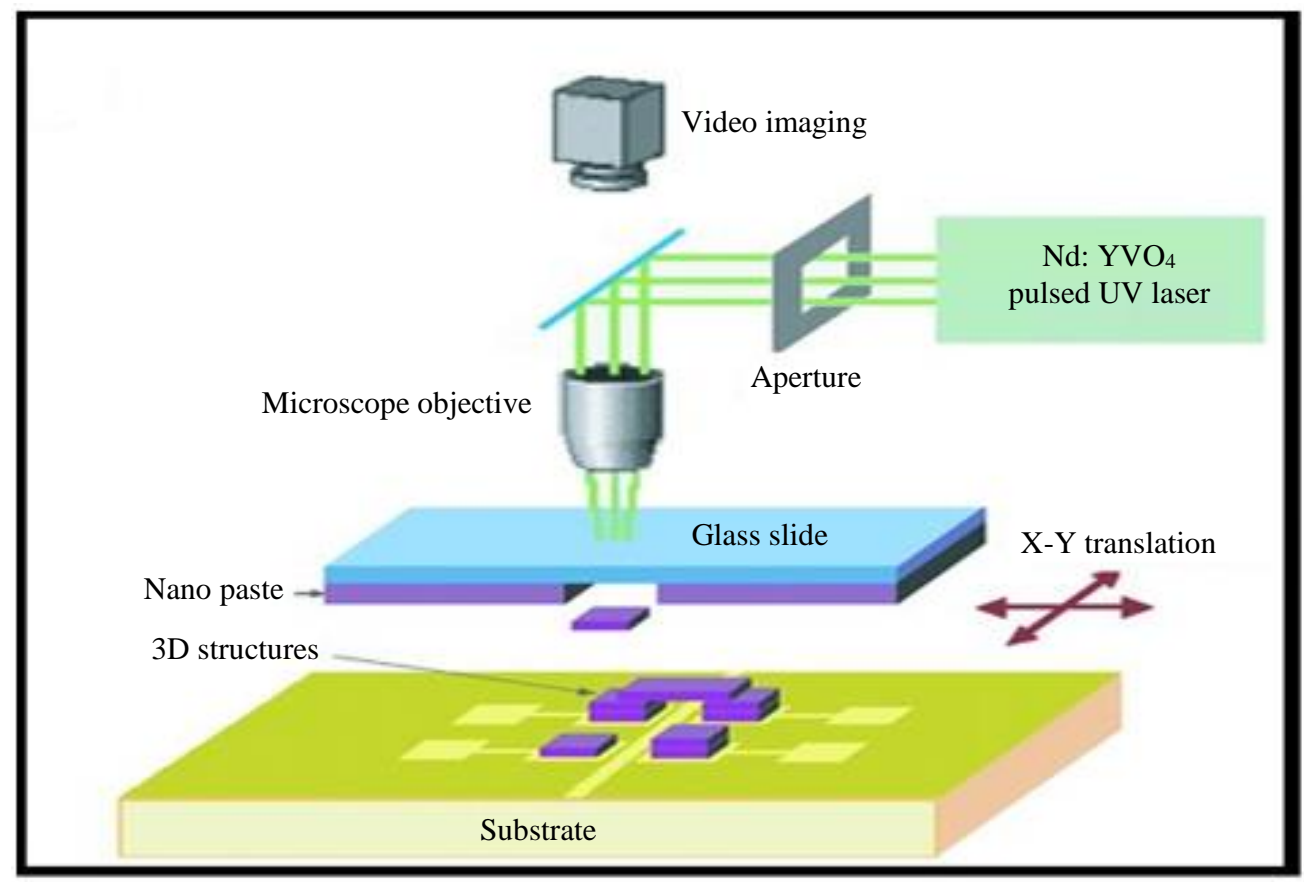

Fig. 8: MAPLE DW technique [(Wang, Auyeung, Kim, Charipar and Piqué, 2010a) @) WILEY-VCH Verlag GmbH and Co. KGaA, Weinheim]

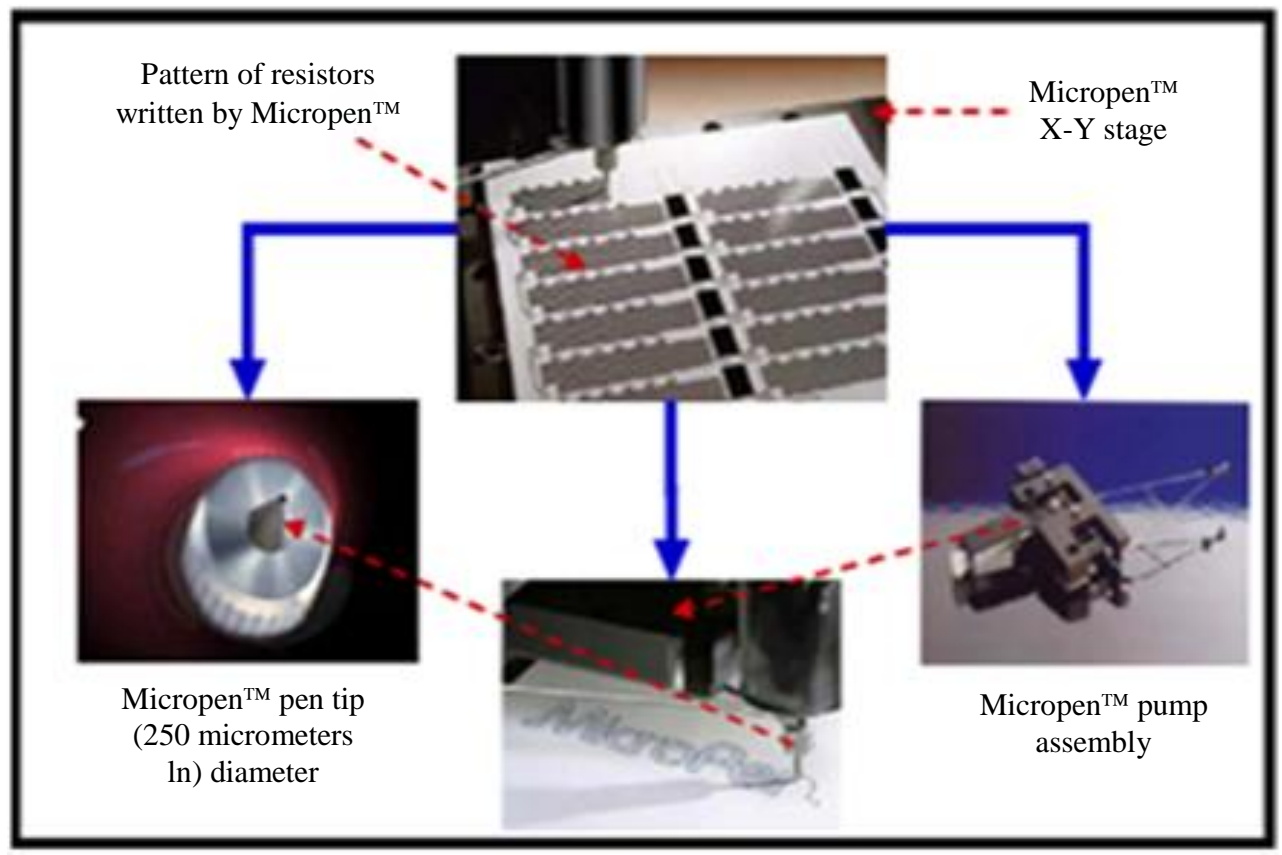

Fig. 9: Micropen DWsystem [(Micropen TM manual, n.d.) @2019 MicroPen Technologies Corporation] 


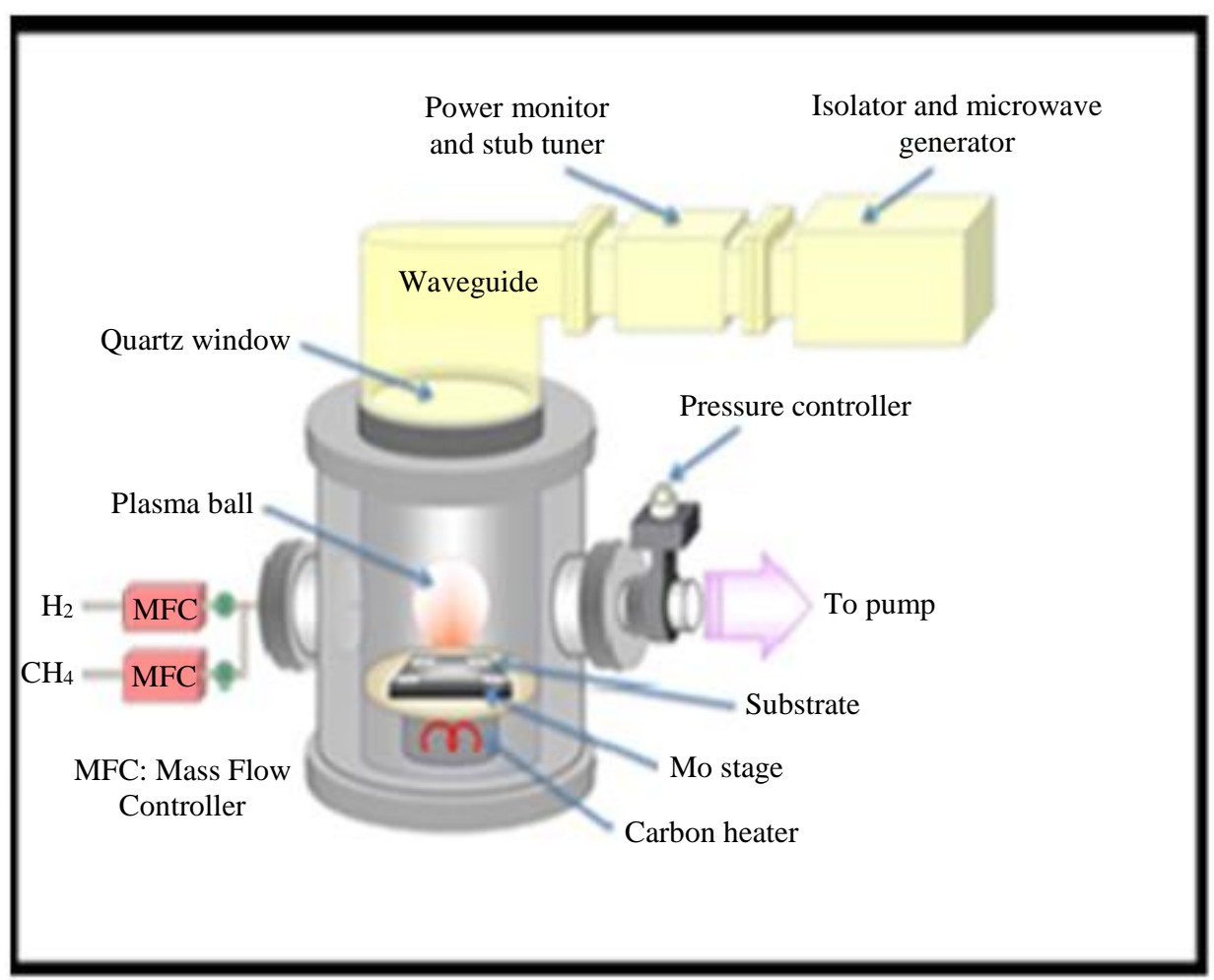

Fig. 10: Laser CVD system [(Hiramatsu et al., 2007) Copyright (C) 2017 IOP Publishing]

Laser chemical vapor deposition (CVD) technique is used for direct writing of thin films of various materials on the surface of a substrate by inducing chemical reactions in a reactant with the guidance of a laser beam. In microelectronic industries, laser CVD is used broadly for depositing thin films of various metals, insulators and semiconductor materials (Piner et al., 1999), (Mazumder, 2013). Figure 10 illustrates the schematic of a laser CVD system. Based on the chemical mechanism involved laser CVD is categorized into two types, (1) pyrolytic LCVD and (2) photolytic LCVD. With laser CVD technique the surface of the substrate can be modified by depositing thin films of desired electrical, optical and mechanical properties. Applications of laser CVD include applying corrosion, wear-resistant and oxidation coatings of various materials on substrate (Mazumder, 2013). In Dip Pen Nanolithography (DPN) technique an atomic force microscope tip is used to pattern molecules directly on a range of substrates with a variety of inks (Piner et al., 1999). Schematic of DPN technique is illustrated in Fig. 11. This technique has the ability to place the molecules selectively at specific sites within a particular structure. Applications of this technique include: Nanoscale sensor fabrication, electronics, biosensor functionalization and cell generation (Piner et al., 1999).
The plasma spray technique is used for applying metallic and non-metallic coatings. In this technique the molten material is spared onto a surface to provide a coating. Initially, powder particles are melted with gas or heat and then the molten particles are accelerated with a high velocity to impact on the surface of the substrate to form a coating (Ružić et al., 2012). Figure 12 illustrate the schematic of plasma process. This technique uses wide variety of materials such as metals, composites, polymers and ceramics. With this technique multimaterial 3D patterns can be produced without the need for pre-masking. Different electronic structures, antennas, sensors and conductors can be embedded on 3D structures (Ronkainen, n.d.).

Ink-jet printing technology can dispense fluid at rates of $1 \mathrm{MHz}$ for continues droplets and $0-25 \mathrm{KHz}$ per second for single droplets on demand to pattern materials in 3D. This technique includes a wide variety of materials such as polymers, liquid metals, optical materials and biomedical reagents. In continuous inkjet technique, drops are produced continuously and their paths are varied by the amount of charge applied. In drop-on-demand ink-jet technique, droplets are produced as needed (on demand) by applying the voltage only when a drop is desired (Pique and Chrisey, 2001). Figure 13 illustrates the schematic of types of ink-jet printing techniques. The parameters such as 
drop size, frequency, velocity, substrate characteristics and printing sequence has a significant role in the development of ink-jet printing techniques. Complex 3D patterns can be fabricated without the need for masks, tooling and dies. Applications include: Solder jetting, fabrication of sensors, passive electronic components (resistors, capacitors and inductors) and batteries (Furlani, n.d.), (Lewis, 2006). Applications of DW techniques are found in defense electronics, chemical sensors, semiconductors, medicine and optoelectronics. DW techniques are used in electronics industry because of its capabilities which include miniaturization, rapid prototyping and surface flexibility. The materials include pastes and inks that consist of a combination of powders, binders, solvents, dispersants flake and nan powders (Desai et al., 2012), (Desai and Lovell, 2012), (Adarkwa and Desai, 2016), (Desai and Lovell, 2008; 2006; 2007), (Esho and Desai, 2012).

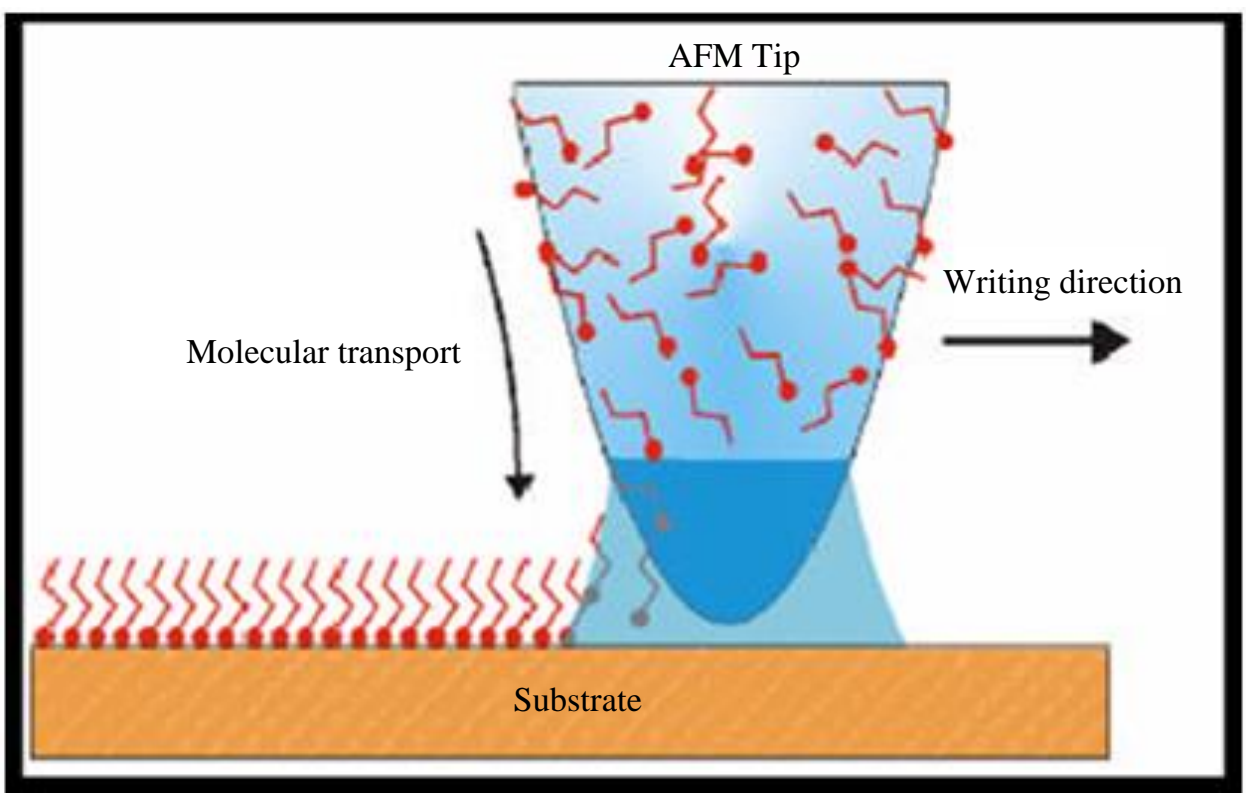

Fig. 11: DPN system [(Piner et al., 1999) Copyright () 1999, The American Association for the Advancement of Science]

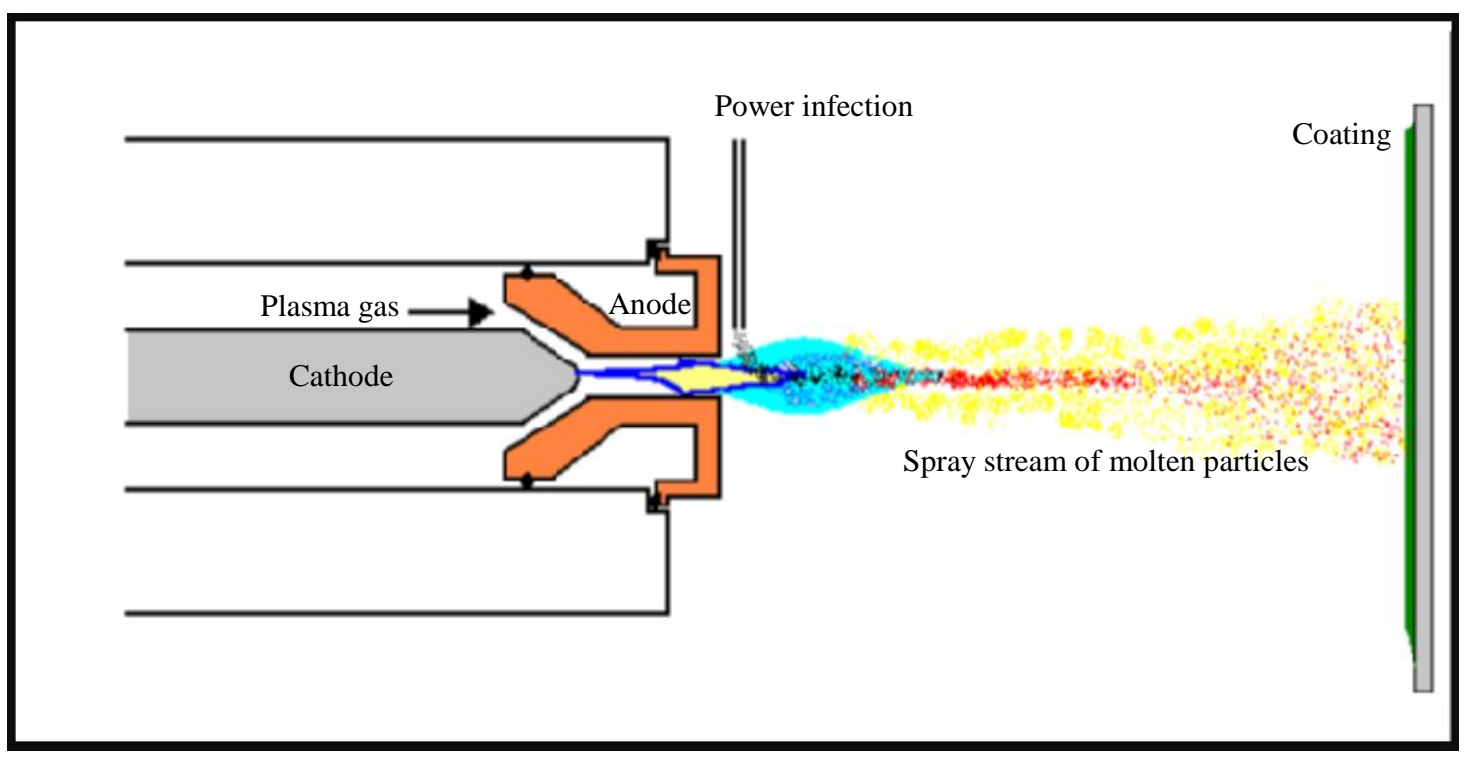

Fig. 12: Schematic diagram of Plasma spray [(Fauchais et al., 2014) Copyright $@$ C Gordon England] 


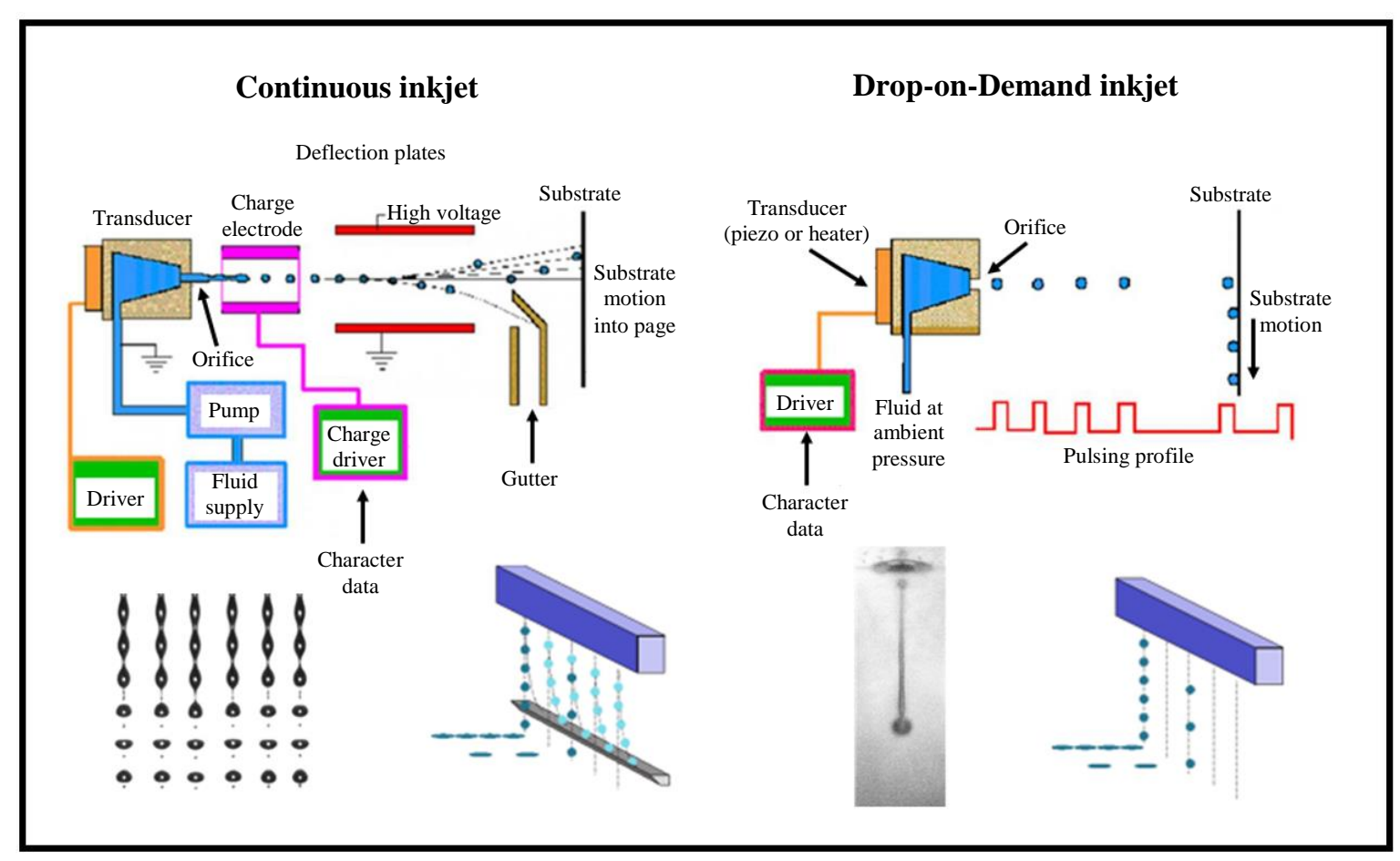

Fig. 13: Ink-jet DW system [(Furlani, n.d.) (C) 2019 University at Buffalo]

\section{Surface Properties of AM Processes}

Surface texture metrology plays a key role in AM manufacturing processes and parts production. The surface quality of parts produced by different AM process has a profound impact on local microstructure, surface irregularity, internal anomaly, product accuracy, functionality and post-processing steps. The factors affecting the surface quality include material properties, particle size range and distribution, part orientation, layer thickness, STL file preparation, surface angle, finish type, scanning parameters and post-processing (Townsend et al., 2016), (Udroiu et al., 2019). The surface microstructure has an influence on the mechanical properties such as tensile strength, yield strength, fatigue strength, compressive properties, crack extension, shear resistance, harness and ultimate strength of the AM production parts. The effect of microstructure on the ultimate performance, durability and reliability of AM production parts was investigated by several researchers (Kahlin, 2017), (Chan, 2015). Calignano et al. investigated the influence of process parameters (power, hatching distance and scan speed) on Aluminium alloy (AlSi10Mg) surface roughness using Direct Metal Laser Sintering (DMLS). Figure 14 clearly illustrates that with decrease in the hatching distance and laser scanning speed the presence of necks or voids reduced leading to a superior surface (Calignano et al., 2013).
Chan et al. and Edward et.al studied the effect of roughness and surface porosity on the fatigue life of titanium alloy material fabricated with laser beam melting (LBM) and electron beam melting (EBM) respectively. The results of these studies reported that the fatigue life of the $\mathrm{Ti}$ alloy part fabricated with $\mathrm{AM}$ techniques can be reduced by rough surface finish (Edwards and Ramulu, 2014), (Chan et al., 2013). The characterization and measurement of surface texture for AM production process is arduous as the manufactured parts must comply practice guidelines, design standards and specifications. Different types of characterizations such as areal and texture can be used to better understand the capabilities of particular AM technologies. Development of AM surface texture good practice specifications, guidance and standards is necessary for the profound understanding and optimization of AM technology and processes (Shi et al., 2016).

\section{Applications}

This review provides the recent developments of 3D printing applications in different areas such as electronics, medical, aerospace, automobile, manufacturing, construction, food industry and consumer products. A comprehensive overview of all the $3 \mathrm{D}$ printing application conducted by researchers and industries is provided. 

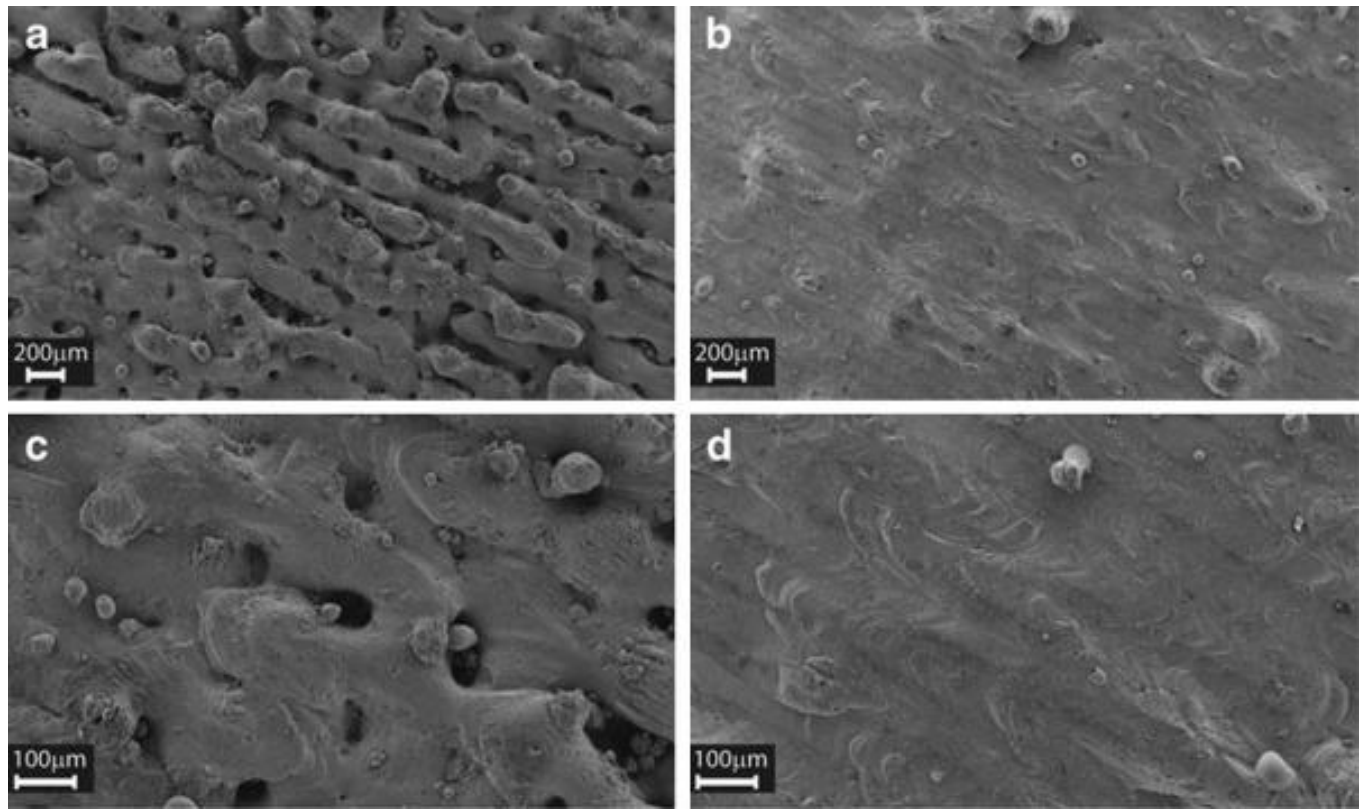

Fig. 14: Field emission SEM images of A1Si10Mg DMLS surfaces. (a and c) Scan speed $1000 \mathrm{~mm} / \mathrm{s}$, laser power $190 \mathrm{~W}$, hatching distance $0.2 \mathrm{~mm}$, Ra $24 \mu \mathrm{m}$, (b and d) Scan speed $800 \mathrm{~mm} / \mathrm{s}$, laser power $190 \mathrm{~W}$, hatching distance $0.1 \mathrm{~mm}, \mathrm{Ra} 14 \mu \mathrm{m}$ [(Calignano et al., 2013) Creative Commons Attribution License (CC BY)]

\section{Electronics}

3D printing electronics offer great potential to build complex object with multiple functionalities. It has shown unique ability to fabricate embedded electronics, 3D structural electronics, conformal electronics, stretchable electronics, ceramic electronic etc., as shown in Fig. 15 (Lehmhus et al., 2016), (Thompson and Yoon, 2013), (Tan et al., 2019), (Wang et al., 2010), (Ota et al., 2016). Over the past five years, a large number of studies and efforts regarding 3D printing electronics have been carried out by both academia and industry (Zheng et al., 2013), (Ladd et al., 2013), (Yang et al., 2018), (Skylar-Scott et al., 2016), (Lewis et al., 2006), (Lifton et al., 2014). To fabricate printed flexible and stretchable 3D electronic devices with desired characteristics and performance, the selection of ink materials, substrates and the printing process is of paramount importance. A significant advancement has been achieved in $3 \mathrm{~d}$ printing of embedded, 3D structural and stretchable electronics (Desai et al., 2013), (Ahn et al., 2009), (Muth et al., 2014), (Flowers et al., 2017), (Jiang et al., 2018), (Parupelli and Desai, 2017), (McKenzie and Desai, 2018), (Esho et al., 2011), (McKenzie et al., 2017), (Desai et al., 2014). 3D printed electronic components have multiple properties such as mechanical characteristics, embedded electrical and optical functions and complex structures (Lu et al., 2018). A hybrid 3D manufacturing system that integrates stereolithography (SL: 3D Systems SL 250/50) and direct write (DP: nScrypt) technology was developed for fabricating 3D embedded electronic structures (3D 555 timer circuit) (Lopes et al., 2012). An outline on $3 \mathrm{D}$ printing technologies, advances and challenges in multi process 3D printing with respect to multifunctionality and complex geometry was provided by Donald research group.

Multi-functional fabrication process was utilized by numerous researchers for fabricating 3D printable structures with embedded function which include sensors, actuation, thermal management, energy storage, antennas, electromagnetic structures and propulsion (MacDonald and Wicker, 2016). Adams et al. (2011) demonstrated the conformal printing of 3D antenna using metallic inks onto convex and concave hemispherical surfaces whose performances nears Chu limit. An aerosol jet technology is a direct write process capable of depositing functional materials such as metal nanoparticle inks, polymers, adhesives, ceramics and bio-active onto a substrate and print multilayer electronic circuits. Metallic traces as low as 10 microns or as large as a centimeter wide can be deposited on planar, nonplanar, 3D surfaces and orthogonal plane surfaces (Paulsen et al., 2012). A microchip patch antenna was fabricated by combining fused filament fabrication and ultra-metal wire mesh embedded approach. The gain of the patch antenna was $5.5 \mathrm{~dB}$ at the resonance peak (Liang et al., 2015). Active electronic components such as transistors, diodes, silicon-controlled rectifiers, operational amplifiers, light-emitting diodes and batteries, etc. have 
the ability to control and amplify the flow of electric charge (Saengchairat et al., 2017), (Boley et al., 2014). Capacitive sensors can be used for applications such as material sensing, biomedical sensing, human interface devices, electronics characterization and environmental sensing (Rahman et al., 2016), (Shemelya et al., 2015). Electromechanical devices such as humidity, pressure, temperature, skin-like and dry electrode sensors can be printed in micro to macro scale using AM (O'Donnell et al.,
2016). Flexible electronics such as cellulose nanofibrilbased coatings of woven cotton fabrics were demonstrated using inkjet printing for e-textile manufacturing (Kamyshny and Magdassi, 2019). Kong et al. (2014) reports a simple, but sophisticated 3D extrusion printing method (multi-material) for patterning functional materials such as metal, polymer and semiconductor for fabricating fully $3 \mathrm{D}$ printed lightemitting diodes (LEDs) based on quantum dots.
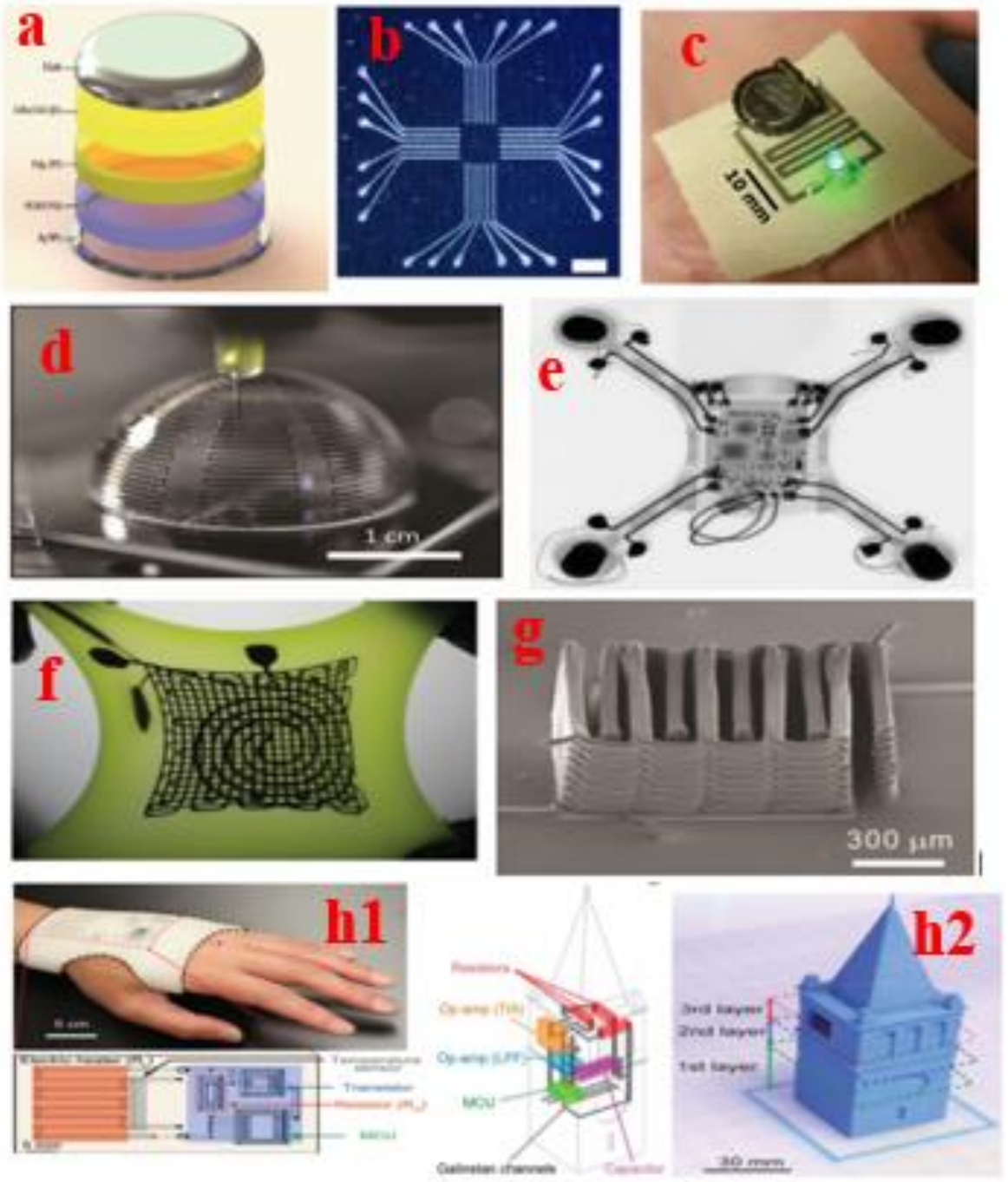

Fig. 15: (a). 3D-printed quantum-dot-based light-emitting diodes (QD-LEDs) [(Kong et al., 2014) Copyright (C) 2014, American Chemical Society], (b). Direct writing of AgTPU electrodes in a 24-pad wiring scheme with electrode widths of $100 \mu \mathrm{m}$ (scale bar $=2 \mathrm{~mm}$ ) [(Valentine et al., 2017) (C) 2017 WILEY-VCH Verlag GmbH and Co. KGaA, Weinheim], (c). Inkjetprinted circuit on woven cotton fabric using Ag NP ink [(Nechyporchuk et al., 2017) Copyright (C) 2017, American Chemical Society], (d). Optical image of an antenna on curved surface during the printing process [(Adams et al., 2011) Copyright (c) 2011 WILEY-VCH Verlag GmbH and Co. KGaA, Weinheim], (e). X-ray micrograph of a quad copter drone [Voxel8], (f). Flexible strain and pressure sensor [(Muth et al., 2014b) (C) 2014 WILEY-VCH Verlag GmbH and Co. KGaA, Weinheim], (g). SEM images 16-layer interdigitated LTO-LFP electrode architectures [(K. Sun et al., 2013) Copyright ( 2013 WILEY-VCH Verlag GmbH and Co. KGaA, Weinheim], (h1). Smart glove with temperature sensor, (h2). 3D tower structure with embedded Microcontroller Unit (MCU), Low-Pass filter (LPF) and trans-impedance amplifier (TIA) [(Ota et al., 2016) (C) 2016 WILEY-VCH Verlag GmbH and Co. KGaA, Weinheim] 
AM technologies enables designers, researchers and industries to fabricate innovative electronic components with complex geometries, customized design, on any surface (linear, circular and curvilinear). The literature provided in this section clearly illustrates the advancement of AM in electronics by various researchers and industries which would not have been feasible through conventional manufacturing processes. Future work would be to address the challenges of using novel materials with new AM techniques for fabricating fully functional innovative electronic components in a single build sequence which can withstand harsh environmental conditions.

\section{Medical Industry}

Scaffold fabrication method, biocompatibility, mechanical performance and bioactivity of materials are crucial for tissue engineering of 3D organs. 3D bio fabrication methods can be used for making complex patient specific bone tissue engineering scaffold with precise control over spatial content and microarchitecture. Materials such as metals, ceramics, hydrogels, polymers and composites are used for tissue engineering (Desai and Harrison, 2009), (Desai et al., 2010b), (Perkins et al., 2011), (Perkins et al., 2015), (Turnbull et al., 2018), (Aljohani and Desai, 2019), (Desai et al., 2008a), (Esho and Desai, 2012), (Desai et al., 2008b). A research group from Chalmers University of Technology have demonstrated the use of nanocellulosebased bio ink for 3D bioprinting with living cells in a meniscus shaped structure was successfully printed (Markstedt et al., 2015). Additive manufacturing methods are capable of fabricating complex tissue structures to repair or replace injured or diseased or damaged human tissues and organs (Melchels et al., 2012), (Perkins et al., 2009), (Desai et al., 2010a), (Shengjie et al., 2009), (Perkins et al., 2011), (Adarkwa et al., 2014), (Parupelli et al., 2019). 3D images of the bone can be reconstructed using CT and MRI scans and a 3D prototype of the bone can be fabricated layer-by-layer using AM. Application of additive manufacturing in orthopedic include in areas such as surgical guides, patient-specific instruments, custom implants, bone defect, anatomic models for the planning of surgery, osteochondral and chondral defect, etc. (Javaid and Haleem, 2018b), (O'Brien, 2011), (Melchels et al., 2010), (Cox et al., 2015). Although, 3D bioprinting is in its early developmental stage, it is a promising tool in biomedical tissue engineering field as it offers to engineer complex 3D biological constructs. Over the past five year's significant advances have been achieved by various researchers in developing state of the art bio fabrication platform for printing biomimetic structures as shown in Fig. 16. A variety of biomaterials, growth factors and cells were utilized for making 3D biostructures (Zhu et al., 2016), (Jardini et al., 2014), (Javaid and Haleem, 2018a), (An et al., 2015), (Bishop et al., 2017), (Singh and Ramakrishna, 2017), (Aimar et al., 2019), (Trevisan et al., 2018), (Dodziuk, 2016), (Cox et al., 2015), (Lewis, 2006), (Javaid and Haleem, 2018b), (Ventola, 2013), (Zuniga et al., 2015), (Salmi, 2013). A research group at Princeton University used 3D printing for fabricating a bionic ear with cellseeded hydrogel matrix, along with a conducting polymer (intertwined). The printed ear demonstrates enhanced auditory sensing capable of receiving electromagnetic signals (hertz to gigahertz frequency range) (Mannoor et al., 2013).

AM technologies have demonstrated significant advancement in the health care industry in the past few years by enabling the production of efficient and costeffective customized surgical implants, hearing guides and dental crows which are unachievable with conventional manufacturing processes. The literature in this section demonstrated the versatility of AM technologies in medical field. Currently some of the applications are in the early development stages such as the bio printing technologies for 3D printing of human organs such as heart, kidney, lungs and other vital organs using biodegradable materials, stems cells and growth factors. The challenges that need to be addressed include materials development, structural strength, speed, size and software skill of using computer-aided-design for optimal part design.

\section{Aerospace}

The adoption of 3D printed parts in aircraft has the potential to contribute significant energy savings and fuel economy from light weight parts. (Nickels, 2015), (Huang et al., 2016), (Vishnu Prashant Reddy et al., 2018), (Seabra et al., 2016), (Dijk, 2016), (Angrish, 2014), (Brandl et al., 2010). The Materials and Manufacturing Directorate of the Air Force Research Laboratory (AFRL/ML) has been using the fusion based AM of metal alloys for producing Ti structures since the late 1990's. (Kobryn et al., 2006). Airbus utilizing metal AM bleed pipes and brackets on its aircraft (3ders, 2014). It has collaborated with Arconic for producing large-scale AM airframe components. It has also partnered with Materialise for manufacturing 3D-printed cabins parts for Airbus's commercial aircraft.

Applications of AM in aerospace and defense include concept modelling and prototyping, printing replacement parts and structures using light-weight, high-strength materials, printing complex engine parts, aircraft wings, repair parts on the battlefield, large structures directly in space and embedding electronic circuit directly on parts as shown in Fig. 17 (U.S. Department of Energy, 2015). Some of the major manufacturers of aircraft such as Boeing (titanium AM parts for commercial and military 
aircraft) and Airbus are adopting the AM technology to achieve quick production process, reduce the supply chain costs, improve functionality and performance and manufacture safe and light-weight products. In the aerospace industry, accuracy and precision are crucial for the passenger's safety and success of the business (Huang et al., 2012), (Uriondo et al., 2015), (Cotteleer, 2014). A world leader in large format 3D printing, BigRep has partnered with Etihad Airways Engineering to advance the use of AM technology in aerospace for printing new aircraft cabin interior parts, as well as for the retrofit market. GE aviation has been using AM technology for manufacturing engine components such as fuel nozzles in mass volume. Other major companies such as Rolls-Royce and OEMs are utilizing AM for the development of 3D-printed structures (Wimpenny et al., 2016). Emirates has collaborated with 3D systems and utilized selective laser sintering (SLS) AM technology for producing aircraft cabin air vent grills for onboard trials and video monitor shrouds (Benedict, 2017).
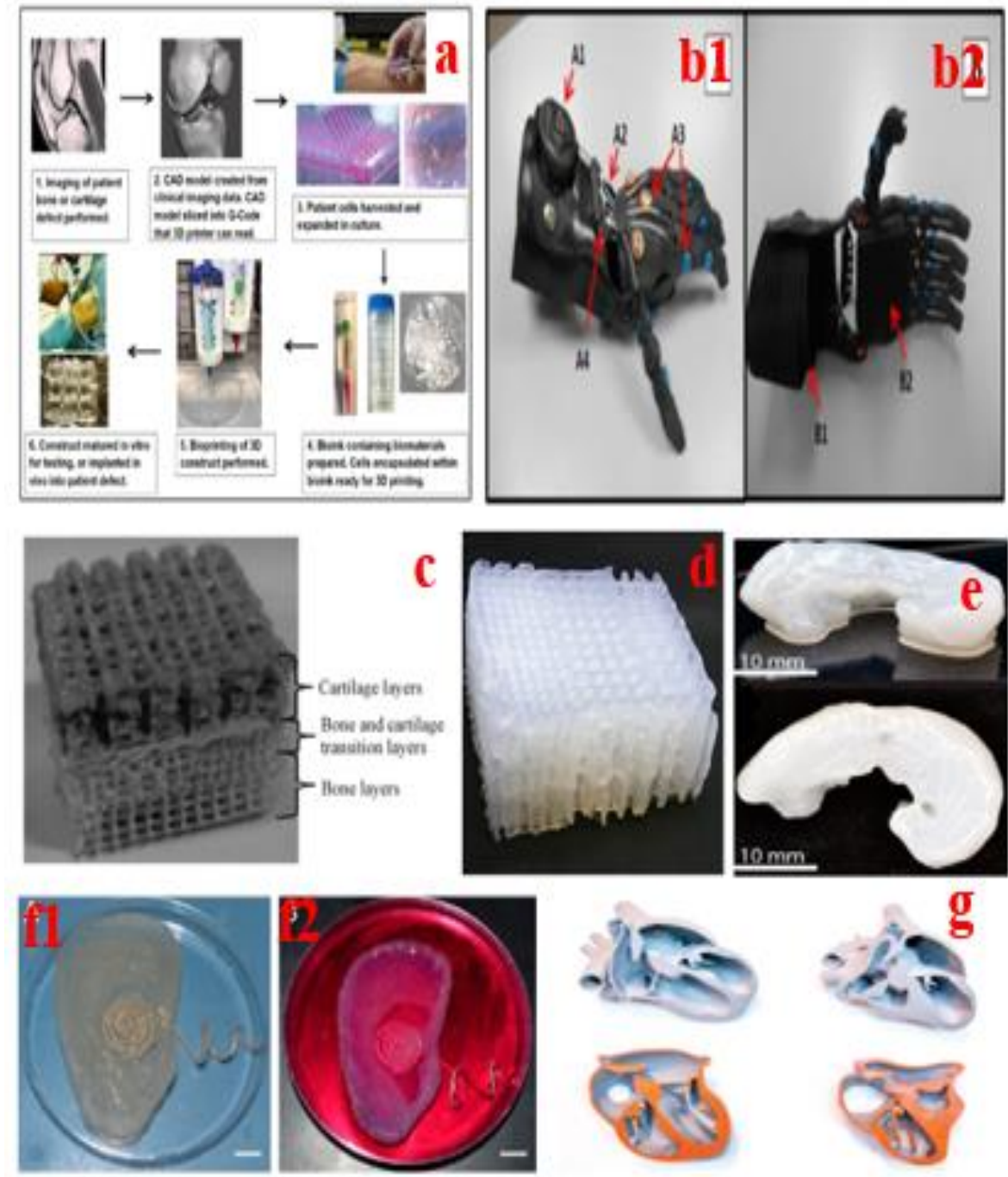

Fig. 16: (a). Bio-printing process for fabrication of 3D organs [(Turnbull et al., 2018b)], (b1) (b2). 3D printed prosthetic hand with top and bottom view [(Zuniga et al., 2015) Copyright (c) Zuniga et.al: licensee BioMed Central. 2015], (c). Functionally gradient osteochondral scaffold [(Chen et al., 2015) Copyright (C) 2015, Institute of Automation, Chinese Academy of Sciences and Springer-Verlag Berlin Heidelberg], (d). Functionally gradient cellulose nanocrystal hydrogel scaffold with pore sizes: 0.5-1-1.5-2 mm [(Sultan and Mathew, 2018) Copyright (C) Creative Commons], (e). 3D printed sheep meniscus [(Markstedt et al., 2015) Copyright (c) 2015, American Chemical Society], (f1). 3D printed ear after printing, (f2). 3D printed ear during in vitro culture [(Mannoor et al., 2013) Copyright ( 2013 , American Chemical Society], (g). Two cardiac 3D models opened at the level of the fourchamber view (left, normal fetal heart; right, the heart exhibiting hypoplastic left heart syndrome based on aortic atresia) [(Dodziuk, 2016) Copyright @ 2016 Polish Society of Cardiothoraic Surgeons and editors of the Polish Journal of Cardio-Thoracic surgery] 

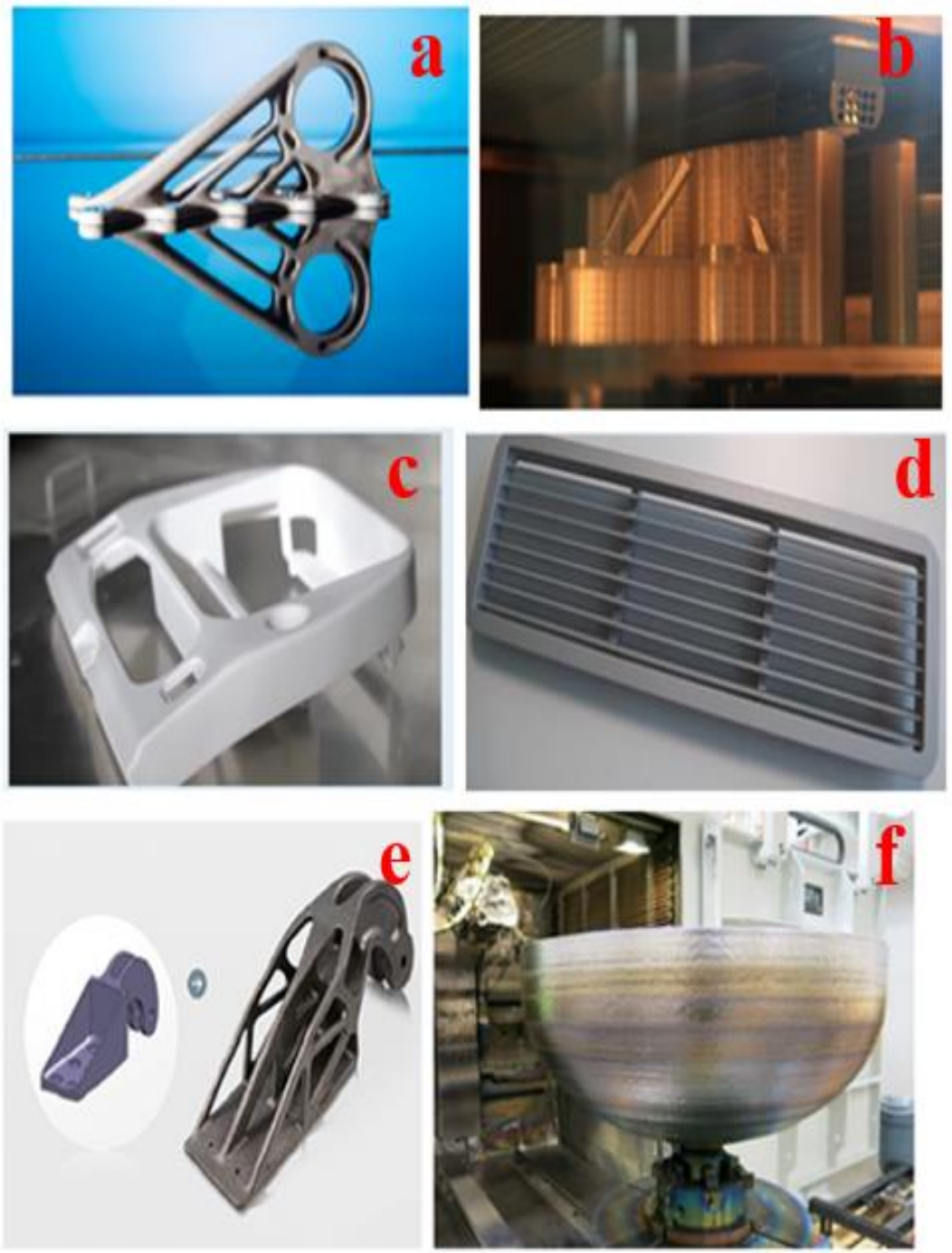

Fig. 17: (a). Airbus A350 XWB titanium cabin bracket manufactured using LaserCUSING technology [Copyrights (C) (Airbus, 2016)], (b). A spacer panel in production at Materialise using FDM technology [Copyrights (C (Materialise, 2018)]. (c). 3D printed video monitor shroud using 3D Systems SLS technology, (d). 3D printed cabin air vent grill developed with UUDS [(Emirates, 2017) Copyrights (C) 3D systems]. (e). Graphic of the conventional design of an assessed steel cast bracket (left) and titanium bracket manufactured using DMLS technology [Copyrights (C) (EOS, 2014)]. (f). 3-D printed titanium dome prototypes at the Lockheed Martin company’s space facility [Copyrights @ (LockheadMartin, 2018)]

AM technologies in aerospace industry have demonstrated crucial developments for manufacturing complex 3D structure without complex tooling and material wastage. AM technologies enable fabrication of aircraft parts such as hinges, interior components, brackets and engine components (fuel nozzles, internal cooling channels and compressors). The literature in this section illustrates the advantages of critical attributes of $\mathrm{AM}$ in aerospace industries for producing complex light weight parts with better fuel efficiencies and functionality for improving the performance of aircraft. Future work includes the development of novel processes, test methods and standards for full utilization of $\mathrm{AM}$ in the aerospace industry.

\section{Construction}

$3 \mathrm{D}$ printing has been used in the construction industry for more than a decade for several ambitious projects. Advantages of $3 \mathrm{D}$ printing in construction include scalability, efficiency, design flexibility, ecofriendly and affordable houses (Buswell et al., 2018), (Lim et al., 2012), (Wu et al., 2016), (Feng and Yuhong, 2014), (Duballet et al., 2017), (Kazemian et al., 2017), (Hager et al., 2016), (Bos et al., 2016), (Kidwell, 2014). Some of the prominent 3D printers used in construction include BetAbram P1, COBOD BOD2, Constructions3D 3D Constructor, CyBe Construction CyBe RC 3Dp, ICON Vulcan II, MudBots 3D Concrete Printer, Total 
Kustom StroyBot 6.2, WASP Crane WASP, Apis Cor, Batiprint3D 3D printer, S-Squared ARCS VVS NEPTUNE, Contour Crafting and XtreeE (Cherdo, 2019). In 2004, University of South California Professor Behrokh Khoshnevis developed a fused deposition modelling 3D printer (Contour Crafting technology), mounted on a robotic arm for extruding concrete layers to build 3D model. Recently in the past few years several concrete based AM techniques have been developed by researchers and industry players for construction applications (Khoshnevis, 2004). A
Russian company, Apis Cor believes that AM is a compelling solution for the housing crisis problem. A 400 sq. feet house as shown in Fig. 18a was 3D printed using fine-grained fiber concrete material by a mobile robot concrete 3D printer in just $24 \mathrm{~h}$ (Cheniuntai, 2018). XtreeE developed a large-scale concrete 3D printer for building ultra-high-performance concrete complex architectures such as a 4-meter high pillar shown in Fig. 18b. which was installed at a public school in Aix-en-Provence, France. (Gosselin et al., 2016), (Gaudillière et al., 2018), (XtreeE, 2017).

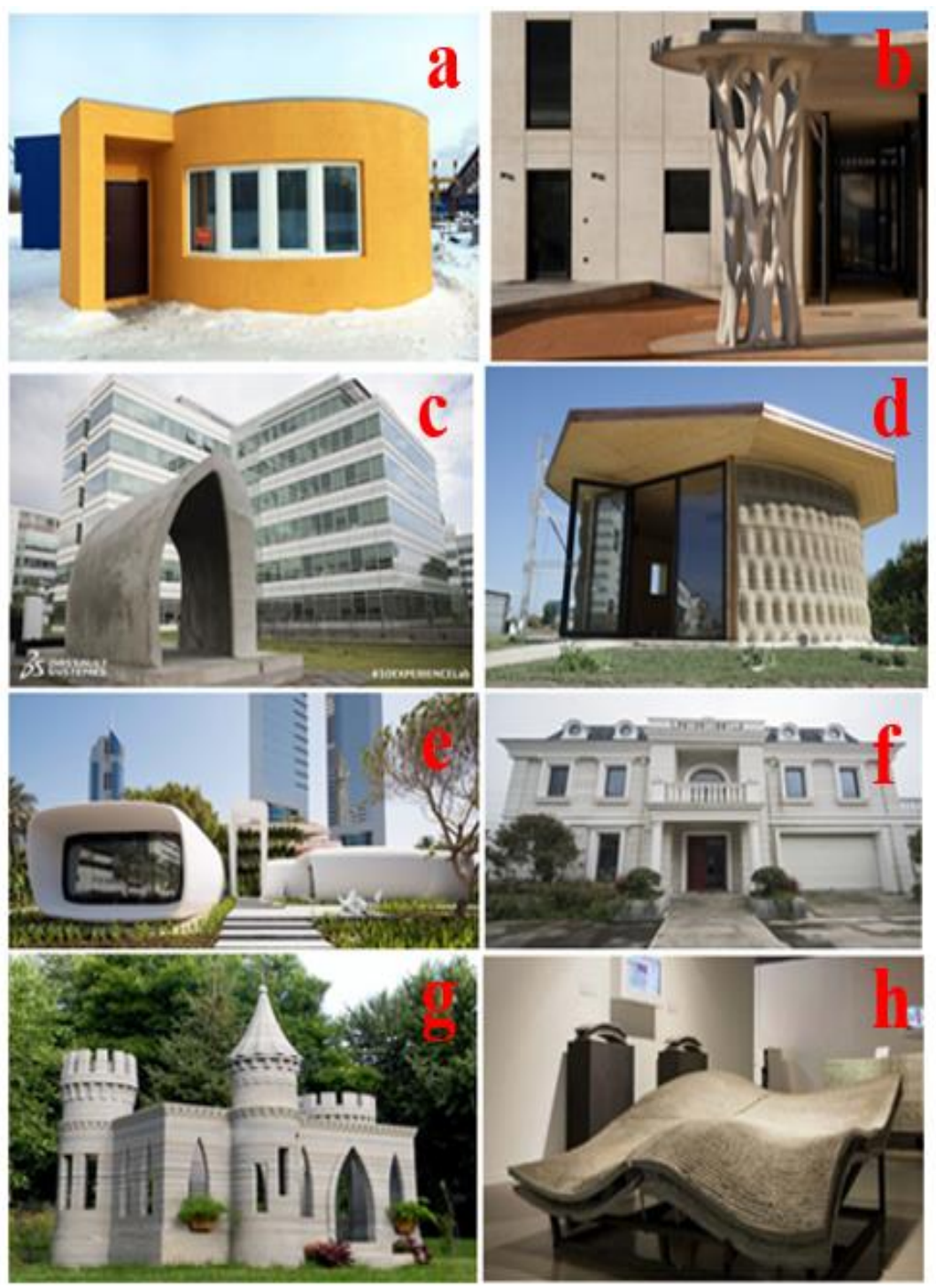

Fig. 18: (a). 3D printed Concrete house by Apis Cor [(Cheniuntai, 2018) Copyrights @ Apis Cor 2018], (b). 3D printed pillar in Aixen-Provence [(XtreeE, 2016) Copyright (C) 2019, Springer Nature Switzerland AG], (c). 3D printed pavilion in Europe [Copyrights (C) (XtreeE, 2017)], (d). 3D printed Gaia house using natural materials such as soil and waste from rice production [(Chiusoli, 2016) Copyrights @) WASP 2016], (e). 3D-Printed Office Building in Dubai [(Musa et al., 2018) Copyrights CDubai/REUTERS], (f). 3D printed Western-style villa [Copyrights @ (Winsun, 2016)], (g). 3D printed Concrete Castle [Copyrights (C) (Rudenko, 2016)], (h). 3D printed concrete surface [(Costanzi, 2016) Copyright () Loughborough University 2016, UK] 
ABB, Dassault Systemes, LarfargeHolcim and XtreeE companies have collaborated by $3 \mathrm{D}$ printing a 3-meter tall Pavilion (Fig. 18c) to demonstrate the potential of sustainable architecture construction. The design of the Pavillion was inspired by nature organic shapes such as trees and coffee beans (XtreeE, 2016). Italian 3D printing company WASP, developed a Crane Wasp 3D printer that can produce homes in different sizes and formats as shown in Fig. 18d. This Gaia house was 3D printed using biodegradable natural materials such as waste from rice production and soil (Chiusoli, 2016)._To date Winsuna, a global firm in China has more than 100 3D printed houses of various types. A western style concrete villa as shown in Fig. 18f. was 3D printed in three days. The world's first 3D printed office building as shown in Fig. 18e was opened in Dubai which was built using a 20 -foot-tall by 120 -foot-long by 20-foot-wide 3D printer in Shanghai (Winsun, 2016), (Musa et al., 2018). In 2014, Minnesota-based Andrey Rudenko 3D printed a $3 \mathrm{~m}$ by $5 \mathrm{~m}$ concrete castle as shown in the Fig. 18g. (Rudenko, 2016). Costanza et.al explored the potential of two manufacturing techniques; concrete additive manufacturing and an adaptable formwork for fabricating complex free-form concrete panels as shown in Fig. 18h (Costanzi, 2016).

Several researchers and industries have embraced the $\mathrm{AM}$ for concrete $3 \mathrm{D}$ printing in the construction field for overcoming the limitations of traditional construction means. The literature in this section elaborates the utilization of AM by various firms for 3D printing of complex architecture shapes, houses with reduction in material wastage, costs, accidents at work and build time. Future work includes the investigation, improvement and refinement of AM concrete process for printing complex shapes, bridges, molds and compound walls, with good finishing and accuracy.

\section{Fashion}

Nowadays due to the advancement in the 3D printing technologies, it is used for producing garments, jackets in the fashion industry and shoe soles in footwear as shown in Fig. 19 (Brookes, 2014), (Valtas and Sun, 2016). In 2015, Danit Peleg used 3D printing for producing fashion collection of garments, Liberty leading The People at the Shankar College of Design. She also introduced the 3D printed garment for sale on her website for $\$ 1500$. The ultimate goal was to make 3D printing more accessible for fashion (Gregurić, 2019a).

The Ministry of Supply in 2016, 3D printed a Jacket without Seams using 3D robotic knitting machine which was sold for $\$ 250$. With the help of 3D printing almost
$15-30 \%$ of the material was saved which would otherwise be wasted with conventional methods (MinistryofSupply, 2016). XYZ Bag, an Italian brand used $3 \mathrm{D}$ printing for producing the customized handbags collection which includes a leather strap attached to a 3D printed shell. Companies like Nike and Adidas are using 3D printing for producing custom fitted shoes. Adidas has partnered with carbon for developing the first 3D printed midsole with complex shape using SLA technology. Companies leading into the arena include Adidas and New Balance, who are starting to 3D print midsoles. Nike, in the meantime, is experimenting with 3D printed "uppers". In 2018, designer Ganit Goldstein collaborated with Stratasys for producing a 3D printed woven shoe which was showcased at Arts of Fashion Competition, San Francisco (Gregurić, 2019a). Corral et al. research group at the University of Arkansas are exploring the abilities of 3D Printing and its viability for consumption in the Fashion Industry. The results of the study illustrated that $3 \mathrm{D}$ printing can be beneficial and feasible to the apparel industry (Walker and Corral, 2017). 3D printing can also be used for printing of jewelry such as rings, bracelets, pendants and other jewelry products in complex design (Adler and Fryé, 2005), (Yap and Yeong, 2014). Fashion designers have demonstrated that by using 3D printing, creative and innovative design patterns in any shape for garments, jackets, jewelry and shoes can be produced. 3D printing provides the complete design freedom for creating revolutionary wear in the future (Sun, 2019), (Kim et al., 2019).

AM process are being employed in fashion industry for producing complex designs due to the advantages of $3 \mathrm{D}$ printing such as degree of freedom, quality design, reduce time and costs, product enhancement and innovation. The literature in this section provides the utilization of AM processes by various fashion designers and small fashion firms in recent times for producing garments, jewelry, footwear, leather goods and accessories. Further improvements in the AM production processes, cost optimization need to be addressed for the full-scale adoption of AM in fashion industry.

\section{Food Industry}

Efforts has been made by various researchers and industries for using 3D printing for creating 3D food printing for personalized food meals. 3D food printing is a way to print customized foods for mass production with enhanced flavor, nutrition and textures. 3D printing of food also known as Food Layered Manufacturer has the potential for producing 3D custom-designed food objects with desired color, shape, flavor, nutrition and 
texture as shown in Fig. 20. Over the past few years several articles and research papers were published related to 3D Food printing (Sher and Tutó, 2015), (Pitayachaval et al., 2018), (Singh and Raghav, 2018), (Godoi et al., 2016), (Tan et al., 2018), (Dankar et al., 2018), (Sun et al., 2015; 2016), (Hemsley et al., 2019), (Avsec, 2016). Cornell Creative Machines Lab 3D printer has been used for printing two identical shaped cookies with different calorie intake by customizing the nutrition based on people biometrics (Lipton et al., 2015), (Lin, 2015). A Silicon Valley Startup named BeeHex developed a 3D printer (Chef 3D -extrusion technique) for printing delicious pizza meals for astronauts during future missions with the aid of NASA grant. BeeHex's bot can also 3D print pastries, dessert decorating and customized nutrition bars (NASA, 2013), (Goehrke, 2017). Food Ink. is the world's first $3 \mathrm{D}$ printing restaurant based on a collaboration of a multi-talented international team including chefs, artists, designers, architects, engineers, industrialists, futurists, technologists and investors (Avsec, 2017). Natural Machines, a Barcelona based company developed a multi-food 3D printer called Foodini by integrating $3 \mathrm{D}$ printing (extrusion technique) with artificial intelligence and food. It is a 3D food printing kitchen appliance that allows to print meal with personalized food and nutrition with minimal food waste (NaturalMachines, 2012).

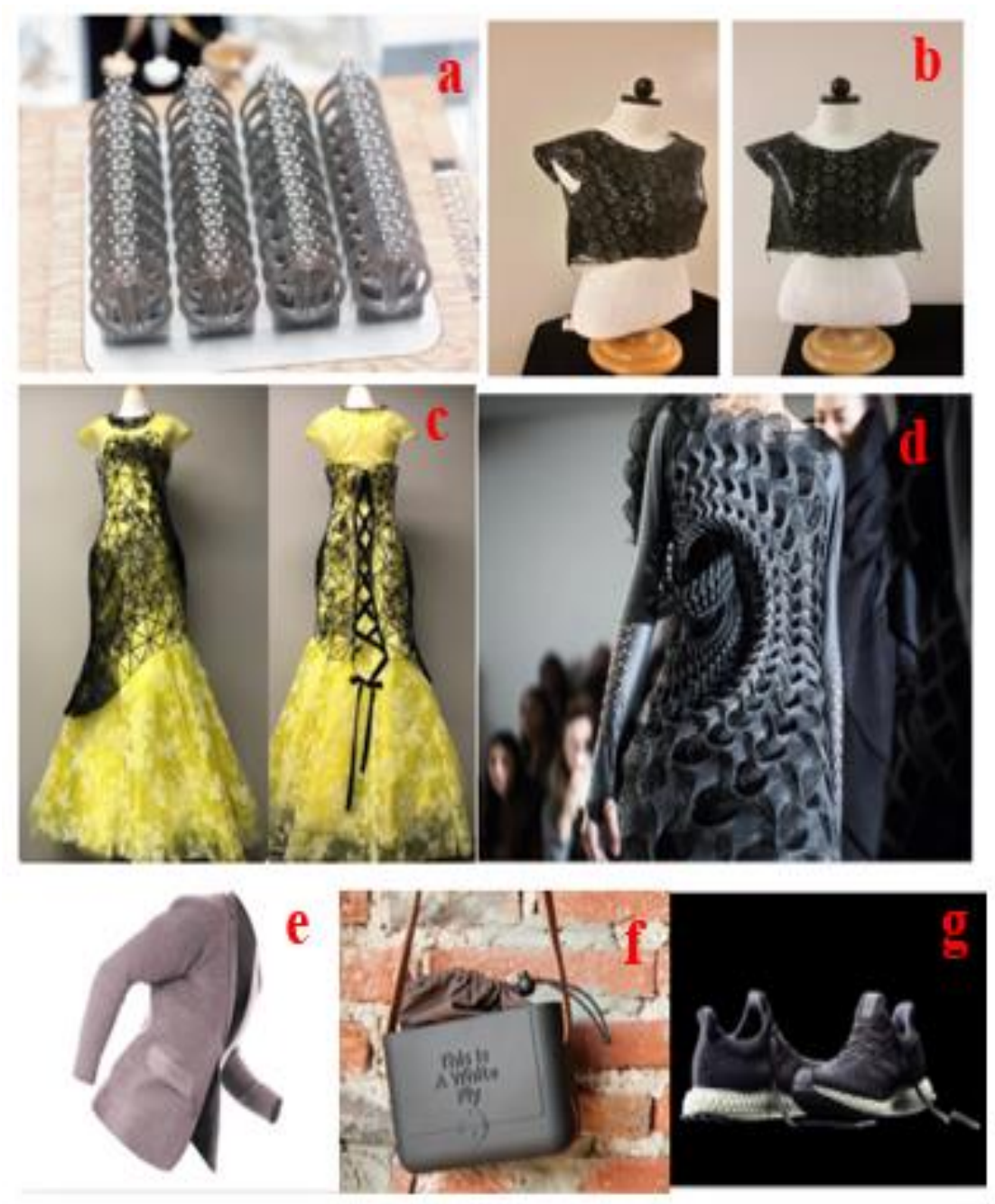

Fig. 19: (a) 3D printed metal rings [(Brookes, 2014) Copyright (C) Kenneth JA Brookes 2014], (b).3D printed garment [(Walker \& Corral, 2017) Copyrights (C) 2017, International Textile and Apparel Association, Inc.], (c). 3D printed dress with complex design [(Kim et al., 2019) Copyrights @ S Springer 2019], (d). The futuristic Pangolin 3D printed dress [(Swack, 2016) Source: Alexis Day Agency], (e). Ministry of Supply jacket without seams [(Gregurić, 2019a) Source: Ministry of Supply], (f). Dada handbag [(XYZBAG, n.d.) Copyrights @ 2015 XYZCUBE Sas by Nicola Annalisa \& C], (g). Adidas Future craft 4D sneakers [(Adidas, 2017)] 

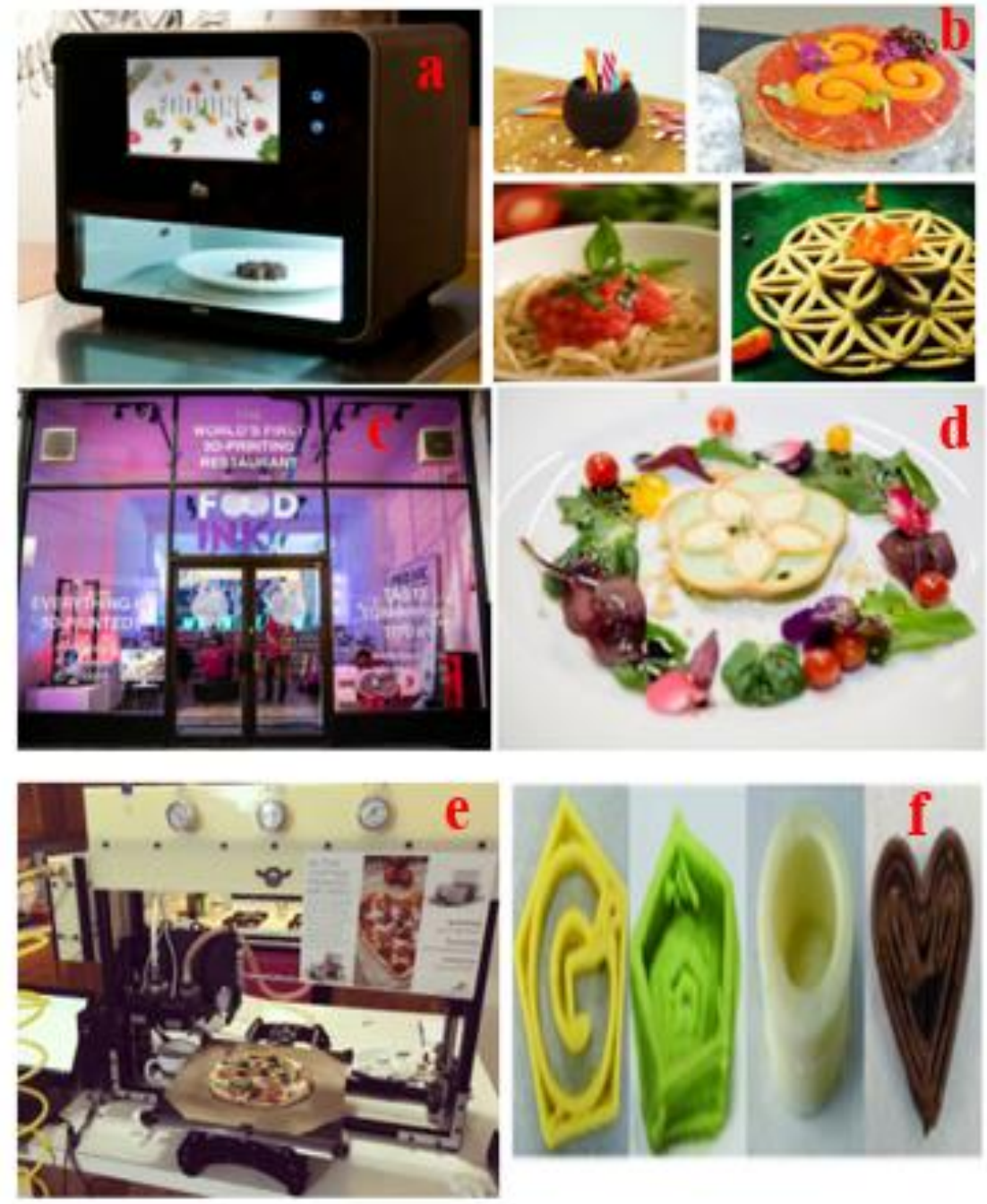

Fig. 20: (a) Natural Machines 3D food printer, (b). 3D printed food using Foodini [(NaturalMachines, 2012)], (c1). Food Ink Restaurant-London, (c2). 3-D printed bread in a sacred-geometric "Flower of Life" design [(Dobrzensky, n.d.)], (d). 3D printed pizza [(Goehrke, 2017), Bee-Hex], (e). 3D printed customized food design samples [Copyright (c) 2017 Jie Sun, Zhuo Peng, Liangkun Yan, Jerry Ying Hsi Fuh, Geok Soon Hong]

AM techniques such as extrusion and binder jetting are employed in food industry for producing customized edible nutritious food products. The literature in this section demonstrates the implementation of AM by various researchers and companies for making pizzas, pastries and food items in a variety of designs. Future work would be addressing the challenges such as food safety, regulations, shell life and development of broad range of ingredients for successfully adopting edible AM in households, restaurants, grocery stores and space.

\section{Automotive}

$3 \mathrm{D}$ printing application in the automotive industry are found in assembly line to develop lightweight car parts, components, replacement, spare parts and prototypes
(Sreehitha, 2017), (Beiderbeck et al., 2018), (Giffi et al., 2014), (Stratasys, 2018), (Ghosh, 2017), (Saunders, 2018), (Sevcik, 2018), (Kerns, 2016). Car manufacturing companies such as BMW, Mercedes-Benz, Bugatti, Chrysler, Honda, GM, Kia, Toyota and Diamler are embracing 3D printing of automotive parts with complex designs. Local Motors, one of the pioneers in 3D printing and autonomous vehicles debuted Strati, first 3D printed electric car in 2014. Recently the world's first 3D printed autonomous shuttle (Olli) as shown in Fig. 20a. were deployed in Sacramento State University campus for university's students, staff and local public. Olli is a safe, smart and sustainable self-driving vehicle integrated with the IBM Watson's advanced cognitive computing capabilities (Rogers, 2014), (Boissonneault, 2019). 

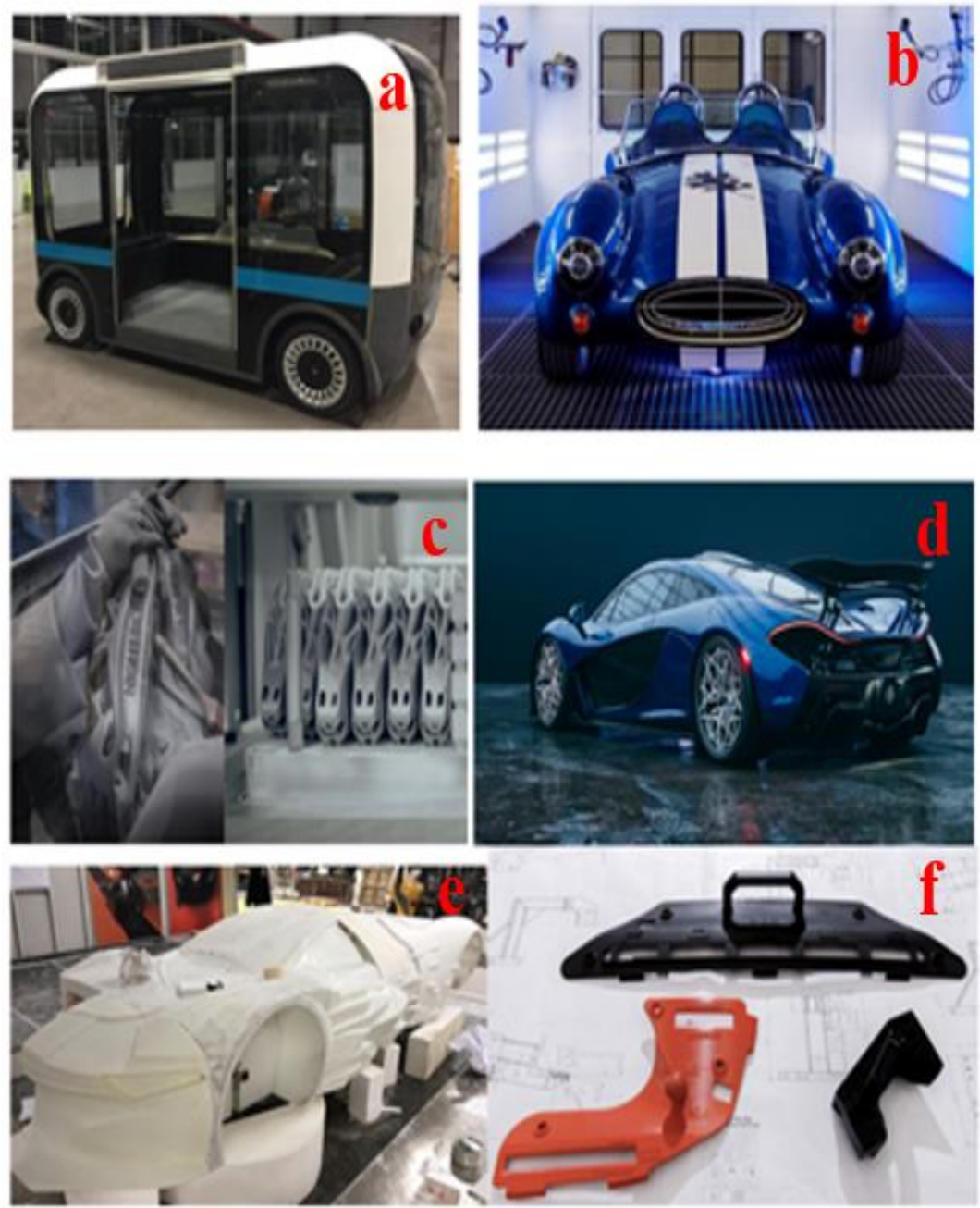

Fig. 21: (a) 3D Printed Shuttle (Olli) [(Rogers, 2014) Copyrights $\odot$ Local Motors], (b). 3D printed Shelby Cobra: ORNL-NASA [(ORNL, 2015)] (c). 3D printed brake caliper and brackets for the folding roof mechanism [(Gregurić, 2019b) Copyrights () BMW Group], (d). 3D printed titanium wheel [(HRE3D+, 2018)], (e). The David Bowie 3D Printed Tribute Concept Car [(Yamamoto et al., 2019) Copyrights (C) Massivit], (f). 3D printed jigs and fixtures for Ford Focus [(Gregurić, 2019a) Copyrights () Ultimaker]

Researcher at the Department of Energy's Oak Ridge National Laboratory 3D printed a Shelby car (Fig. 21b) using the Big Area Additive Manufacturing (BAAM) machine. Shelby was designed to "plug and play" with components such as power electronics, battery, hybrid system designs, wireless charging system and fuel cell technologies, for testing quickly new ideas with ease (ORNL, 2015).

BMW is using metal 3D printing technology for producing complex shape end-use parts such as brake callipers and the brackets parts as shown in Fig. 21c (Gregurić, 2019a). GE Additive collaborated with HRE Wheels and developed the first 3D printed titanium wheel as shown in Fig. 21d. using Electron Beam Melting (EBM) AM technology. This shows the capabilities of AM in creating functional parts with features such as corrosion resistance and higher strength (HRE3D+, 2018). Takumi Yamamto, car designer demonstrated the use of a 3D printing for a full scale concept car, Fig. 21e. as a tribute to musical icon David Bowie with Massivit 1800 Pro 3D printer (Yamamoto et al., 2019). Jigs and fixtures (Fig. 21f) are the basic tools in the automotive industry, mainly used for badges positioning. 3D printing of jigs and fixtures saves time, cost and reduces material waste. For example, Volkswagen saved more than $\$ 200 \mathrm{~K}$ in tooling costs using 3D printing (Goehrke, 2018).

AM technologies in automotive industry have opened up enormous opportunities for producing novel designs, lighter, safer and economical products with reduction in material wastage, cost and lead times which is not achievable by conventional manufacturing techniques. 
The literature in this section reports the adoption and advancements of AM in automotive field in the past few years for building jigs, fixtures, spare parts, car tires, customizes tools, interior parts, car frames, brake calipers and brackets. The future work includes the development of enhanced AM parts with effective product quality, manufacturing large parts and limiting post-processing steps. Thus, AM has the potential to shape the automotive landscape at global scale.

\section{Future Prospects}

In the coming decades, AM will fuel the advancement of Industry 4.0 in shaping the future of global industrial market. Industry 4.0 is an adaptive, cognitive and largely self-optimizing factory (Elhoone et al., 2019). Combining AM with Internet-ofThings, cloud computing, robotics and big data will revolutionize all industry sectors. 3D printing can be seen as one of the crucial milestones in the advancement of industrial manufacturing technology. The professional 3D printers developed so far will continue to advance innovation and promote businesses in diverse industry sectors such as electronics, healthcare, manufacturing, aerospace, automobile, construction, fashion, jewelry, entertainment and food industry.

\section{Conclusion}

Additive Manufacturing (AM) has advanced from a rapid prototyping tool to a manufacturing technology capable of producing functional end-user products. This paper provides a detailed overview of all the AM technologies categorized under the following processes: Photo polymerization, extrusion systems, powder bed fusion, jetting processes, directed energy deposition, sheet lamination and hybrid and direct write AM. Further, the paper provides insights about the significant advancements in a diverse range of fields which include electronics, medical industry, aerospace, construction, fashion, food industry and the automotive industry. This review will promote AM technologies to researchers and industries with recent advancements and prospects of AM processes, materials and capabilities. AM technologies are utilized for a broad extent of applications ranging from printing basic electronic circuits, jigs and fixtures to complex real life applications. These include creating human 3D organs, manufacturing spacecraft engines and 3D vehicles, building large-scale architecture houses and customized nutritious food products. Continuous innovation and advancements in AM will revolutionize the future as AM will play an essential role in the modern economy. Finally, this paper provides notable achievements in AM with a perspective on its future potential.

\section{Acknowledgement}

The authors would like to thank the National Science Foundation (NSF CMMI Awards - 1435649 and1663128) for their support towards this research. We would also like to express our gratitude to the Department of Defense, Air Force Research Laboratory (EPA 16-EPA-RQ-12) for funding support.

\section{Author's Contributions}

SantoshKumar Parupelli: Contributed to the literature review, compilation and writing of the manuscript.

Salil Desai: Designed the overall theme of the article and contributed to the editing of the manuscript.

\section{Ethics}

This article is original and contains unpublished material. The corresponding author confirms that all of the other authors have read and approved the manuscript and no ethical issues involved.

\section{References}

3ders, 2014. 3D printed titanium components now onboard the Airbus A350 XWB. 3D Printing Technology.

3DExperience, 2018. Directed energy deposition - DED, LENS, EBAM. 3DExperience.

Adams, J.J., E.B. Duoss, T.F. Malkowski, M.J. Motala and B.Y. Ahn et al., 2011. Conformal printing of electrically small antennas on three-dimensional surfaces. Adv. Mater., 23: 1335-1340.

DOI: $10.1002 /$ adma.201003734

Adarkwa, E. and S. Desai, 2016. Scalable droplet based manufacturing using in-flight laser evaporation. J. Nanoeng. Nanomanufact., 6: 87-92.

DOI: $10.1166 /$ jnan.2016.1265

Adarkwa, E., S. Desai, J.M. Ohodnicki, A. Roy and B. Lee et al., 2014. Amorphous calcium phosphate blended polymer coatings for biomedical implants. Proceedings of the Industrial and Systems Engineering Research Conference, (ERC' 14).

Adidas, 2017. Carbon and adidas collaborate to upend athletic footwear.

Adler, S. and T. Fryé, 2005. The revolution of CAD/CAM in the casting of fine jewelry. Proceedings of the Santa Fe Symposium on Jewelry Manufacturing Technology, May 17-20, Albuquerque, New Mexico.

Ahlfeld, T., G. Cidonio, D. Kilian, S. Duin and A.R. Akkineni et al., 2017. Development of a clay based bioink for 3D cell printing for skeletal application. Development of the Biopen: A handheld device for surgical printing of adipose stem cells at a chondral wound site. Biofabrication, 9: 034103-034103. DOI: $10.1088 / 1758-5090 / \mathrm{aa} 7 \mathrm{e} 96$ 
Ahn, B.Y., E.B. Duoss, M.J. Motala, X. Guo and S. Park et al., 2009. Omnidirectional printing and of flexible, stretchable, silver microelectrodes spanning. Science, 323: 1590-1593.

Aimar, A., A. Palermo and B. Innocenti, 2019. The role of 3D printing in medical applications: A state of the art. J. Healthcare Eng., 2019: 5340616-5340616. DOI: $10.1155 / 2019 / 5340616$

Airbus, 2016. Pioneering bionic 3D printing. Airbus.

Aljohani, A. and S. Desai, 2019. 3D printing of porous scaffolds for medical applications. Am. J. Eng. Applied Sci., 11: 1076-1085.

DOI: 10.3844/ajeassp.2018.1076.1085

An, J., J.E.M. Teoh, R. Suntornnond and C.K. Chua, 2015. Design and 3D printing of scaffolds and tissues. Engineering, 1: 261-268.

DOI: $10.15302 / \mathrm{j}$-eng-2015061

Angrish, A., 2014. A critical analysis of additive manufacturing technologies for aerospace applications. Proceedings of the IEEE Aerospace Conference, Mar. 1-8, IEEE Xplore Press, Big Sky, MT, USA, pp: 1-6.

DOI: 10.1109/AERO.2014.6836456

Avsec, M.E., 2016. Developments in 3D printing a sector by sector overview.

Avsec, M.E., 2017. Developments in 3D printing a sector by sector overview.

Balla, V.K., S. Bose and A. Bandyopadhyay, 2008. Processing of bulk alumina ceramics using laser engineered net shaping. Int. J. Applied Ceramic Technol., 5: 234-242. DOI: 10.1111/j.1744-7402.2008.02202.x

Beaman, J.J., J.W. Barlow, D.L. Bourell, R.H. Crawford and H.L. Marcus et al., 1997. Solid Freeform Fabrication: A New Direction in Manufacturing. 1st Edn., Kluwer Academic Publishers, Norwell, MA., ISBN-10: 0792398343, pp: 330.

Beiderbeck, D., D. Deradjat and T. Minshall, 2018. The impact of additive manufacturing technologies on industrial spare parts strategies.

Benedict, 2017. Watch how Dubai's emirates is 3D printing aircraft cabin parts using SLS technology.

Bishop, E.S., S. Mostafa, M. Pakvasa, H.H. Luu and M.J. Lee et al., 2017. 3-D bioprinting technologies in tissue engineering and regenerative medicine: Current and future trends. Genes Dis., 4: 185-195. DOI: 10.1016/j.gendis.2017.10.002

Boissonneault, T., 2019. Local motors deploys 3D printed, autonomous Olli shuttles to Sacramento State. 3D Printing Media Network.

Boley, J.W., E.L. White, G.T.C. Chiu and R.K. Kramer, 2014. Direct writing of gallium-indium alloy for stretchable electronics. Adv. Funct. Mater., 24: 3501-3507. DOI: 10.1002/adfm.201303220
Bos, F., R. Wolfs, Z. Ahmed and T. Salet, 2016. Additive manufacturing of concrete in construction: Potentials and challenges of 3D concrete printing. Virtual Phys. Prototyp., 11: 209-225. DOI: $10.1080 / 17452759.2016 .1209867$

Brandl, E., B. Baufeld, C. Leyens and R. Gault, 2010. Additive manufactured Ti-6A1-4V using welding wire: Comparison of laser and arc beam deposition and evaluation with respect to aerospace material specifications. Phys. Proc., 5: 595-606. DOI: $10.1016 /$ j.phpro.2010.08.087

Brookes, K., 2014. 3D print show. Metal Powder Rep., 69: 33-35. DOI: 10.1016/s0026-0657(14)70030-x

Buswell, R.A., W.R. Leal de Silva, S.Z. Jones and J. Dirrenberger, 2018. 3D printing using concrete extrusion: A roadmap for research. Cement Concrete Res., 112: 37-49.

DOI: 10.1016/j.cemconres.2018.05.006

Calignano, F., D. Manfredi, E.P. Ambrosio, L. Iuliano and P. Fino, 2013. Influence of process parameters on surface roughness of aluminum parts produced by DMLS. Inte. J. Adv. Manufact. Technol., 67: 2743-2751. DOI: 10.1007/s00170-012-4688-9

Chan, K.S., 2015. Characterization and analysis of surface notches on Ti-alloy plates fabricated by additive manufacturing techniques. Surface Topography: Metrol. Properties.

DOI: 10.1088/2051-672X/3/4/044006

Chan, K.S., M. Koike, R.L. Mason and O. Toru, 2013. Fatigue life of titanium alloys fabricated by additive layer manufacturing techniques for dental implants. Metallurgical Mater. Trans. A, 44: 1010-1022. DOI: $10.1007 / \mathrm{s} 11661-012-1470-4$

Chen, W.H., Y.Y. Liu, F.H. Zhang, Y.Z. Yu and H.P. Chen et al., 2015. Osteochondral integrated scaffolds with gradient structure by $3 \mathrm{D}$ printing forming. Int. J. Autom. Comput., 12: 220-228. DOI: 10.1007/s11633-014-0853-y

Cheniuntai, N., 2018. What construction 3D printing is: Perspectives and challenges. Apis Cor.

Cherdo, L., 2019. The 13 best construction 3D printers. Aniwaa.

Chiusoli, A., 2016. 3D printing for sustainable living. WASP.

Comb, J., W.R. Priedeman and P.W. Turley, 1994. FDM technology process improvements. Proceedings of Solid Freeform Fabrication Symposium, (FFS' 94), pp: 42-49.

Cormier, D., O. Harrysson and H. West, 2004. Characterization of $\mathrm{H} 13$ steel produced via electron beam melting. Rapid Prototyp. J., 10: 35-41. DOI: 10.1108/13552540410512516

Costanzi, C.B., 2016. 3D printing concrete onto flexible surfaces. Delft University of Technology Faculty. 
Cotteleer, M.J., 2014. 3D opportunity: Additive manufacturing paths to performance, innovation and growth. Additive Manufacturirng Symposium.

Cox, S.C., J.A. Thornby, G.J. Gibbons, M.A. Williams and K.K. Mallick, 2015. 3D printing of porous hydroxyapatite scaffolds intended for use in bone tissue engineering applications. Mater. Sci. Eng. C, 47: 237-247. DOI: 10.1016/j.msec.2014.11.024

Dankar, I., A. Haddarah, F.E.L. Omar, F. Sepulcre and M. Pujolà, 2018. 3D printing technology: The new era for food customization and elaboration. Trends Food Sci. Technol., 75: 231-242. DOI: 10.1016/j.tifs.2018.03.018

Desai, S. and B. Harrison, 2009. Direct-Writing of Biomedia for Drug Delivery and Tissue Regeneration. In: Printed Biomaterials, Narayan, R., T. Boland and Y.S. Lee (Eds.), Springer, New York, pp: 71-89.

Desai, S. and M. Lovell, 2006. Coupled field analysis of a piezoelectric bimorph disc within a CIJ microfabrication process. Proceedings of the IIE Annual Conference and Exhibition, (ACE' 06).

Desai, S. and M. Lovell, 2007. CFD analysis of a continuous inkjet print head for direct write fabrication. Proceedings of the ASME International Mechanical Engineering Congress and Exposition, (ECE' 07), ASME, pp: 209-213.

Desai, S. and M. Lovell, 2008. Multiphysics modeling of a piezoelectric bimorph disc in a direct write fabrication process. Proceedings of the ASME International Mechanical Engineering Congress and Exposition, (ECE' 08), ASME, pp: 437-442.

Desai, S. and M. Lovell, 2012. Modeling fluid-structure interaction in a direct write manufacturing process. J. Mater. Process. Technol., 212: 2031-2040. DOI: 10.1016/j.jmatprotec.2012.05.006

Desai, S., A. Moore, B. Harrison and J. Sankar, 2008b. Understanding microdroplet formations for biomedical applications. Proceedings of the ASME International Mechanical Engineering Congress and Exposition, (ECE' 08), pp: 1-4.

Desai, S., A. Richardson and S.J. Lee, 2010a. Bioprinting of FITC conjugated bovine serum albumin towards stem cell differentiation. Proceedings of the IIE Annual Conference and Expo, (ACE' 10).

Desai, S., J. Perkins, B.S. Harrison and J. Sankar, 2010 b. Understanding release kinetics of biopolymer drug delivery microcapsules for biomedical applications. Mater. Sci. Eng. B, 168: 127-131.

DOI: 10.1016/j.mseb.2009.11.006

Desai, S., J. Sankar, A. Moore and B. Harrison, 2008a. Biomanufacturing of microcapsules for drug delivery and tissue engineering applications. Proceedings of the IIE Annual Conference and Expo, (ACE’ 08), pp: 507-513.
Desai, S., M. Craps and T. Esho, 2013. Direct writing of nanomaterials for flexible Thin-Film Transistors (fTFTs). Int. J. Adv. Manuf. Technol., 64: 537-543. DOI: $10.1007 / \mathrm{s} 00170-012-4425-4$

Desai, S., M. Yang, Z. Xu and J. Sankar, 2014. Direct write manufacturing of solid oxide fuel cells for green energy. J. Environ. Res. Dev., 8: 477-483.

Desai, S., T. Esho and R. Kaware, 2012. Experimental investigation of controlled microdroplet evaporation toward scalable micro/nanomanufacturing. IIE Trans., 44: 155-162. DOI: 10.1080/0740817X.2011.593610

Dijk, V., 2016. Additive manufacturing: Will it be a potential game changer for the aerospace manufacturing industry? A qualitative study of technology adoption.

Dobrzensky, A., (n.d.). The world's first 3d-printing restaurant. Food Ink.

Dodziuk, H., 2016. Applications of 3D printing in healthcare. Kardiochirurgia i Torakochirurgia Polska, 13: 283-293. DOI: 10.5114/kitp.2016.62625

Duballet, R., O. Baverel and J. Dirrenberger, 2017. Classification of building systems for concrete 3D printing. Automat. Constr., 83: 247-258. DOI: 10.1016/j.autcon.2017.08.018

Edwards, P. and M. Ramulu, 2014. Fatigue performance evaluation of selective laser melted Ti-6Al-4V. Mater. Sci. Eng. A, 598: 327-337. DOI: $10.1016 /$ j.msea.2014.01.041

Elhoone, H., T. Zhang, M. Anwar and S. Desai, 2019. Cyber-based design for additive manufacturing using artificial neural networks for Industry 4.0. Int. J. Product. Res. DOI: $10.1080 / 00207543.2019 .1671627$

Emirates, 2017. Emirates brings in a step change in 3D printing for aircraft parts.

Engstrom, D.S., 2012a. Additive manufacturing research group: Binder jetting. Loughborough University.

Engstrom, D.S., 2012c. Powder bed fusion. Loughborough University.

EOS, 2014. Aerospace: EADS and EOS - study demonstrates savings potential for DMLS in the aerospace industry.

Esho, T. and S. Desai, 2012. Laser based microdroplet evaporation towards scalable micro and nano manufacturing. Proceedings of the 62nd Industrial and Systems Engineering Research Conference, (ERC' 12), pp: 1-8.

Esho, T., S. Desai and M. Craps, 2011. Direct writing of enriched single walled carbon nanotubes towards thin film transistors (TFTs). Proceedings of the 61st Annual IIE Conference and Expo, (ACE' 11).

Fauchais, P.L., J.V.R. Heberlein and M.I. Boulos, 2014. Thermal Spray Fundamentals: From Powder to Part. 1st Edn., Springer, New York, ISBN-10: 0387689915, pp: 1566. 
FDM, 2008. Fused deposition modeling. CustomPartNet.

Feng, L. and L. Yuhong, 2014. Study on the Status Quo and problems of $3 \mathrm{D}$ printed buildings in China. Global J. Human-Social Sci.: H Interdisciplinary.

Feygin, M. and B.H. Freeform, 1991. Laminated Object Manufacturing (LOM): A simpler process. Proceedings of the International Solid Freeform Fabrication Symposium, (FFS' 91).

Flowers, P.F., C. Reyes, S. Ye, M.J. Kim and B.J. Wiley, 2017. 3D printing electronic components and circuits with conductive thermoplastic filament. Additive Manuf., 18: 156-163.

DOI: 10.1016/j.addma.2017.10.002

Furlani, E.P., (n.d.). Inkjet systems. University of Buffalo.

Gaudillière, N., R. Duballet, C. Bouyssou, A. Mallet and P. Roux et al., 2018. Large-Scale Additive Manufacturing of Ultra-High-Performance Concrete of Integrated Formwork for TrussShaped Pillars. In: Robotic Fabrication in Architecture, Art and Design, Willmann, J., P. Block, M. Hutter, K. Byrne and T. Schork (Eds.), Springer, Cham. pp: 459-472.

Ghazy, M.M., 2012. Development of an Additive Manufacturing Decision Support System (AMDSS). PhD Thesis, Newcastle University.

Ghosh, A., 2017. Additive manufacturing in the automotive industry.

Gibson, I., D. Rosen and B. Stucker, 2012. Additive Manufacturing Technologies: 3D Printing, Rapid Prototyping and Direct Digital Manufacturing. 1st Edn., Springer.

Giffi, C.A., B. Gangula and P. Illinda, 2014. 3D opportunity in the automotive industry. Deloitte University Press.

Godoi, F.C., S. Prakash and B.R. Bhandari, 2016. 3d printing technologies applied for food design: Status and prospects. J. Food Eng., 179: 44-54.

DOI: $10.1016 /$ j.jfoodeng.2016.01.025

Goehrke, S., 2018. Additive manufacturing is driving the future of the automotive industry. Forbes.

Goehrke, S.A., 2017. NASA-born BeeHex makes 3D printed pizza palatable, brings R\&D operations to Ohio. 3D Print.

Gosselin, C., R. Duballet, P. Roux, N. Gaudillière and J. Dirrenberger et al., 2016. Large-scale 3D printing of ultra-high performance concrete - a new processing route for architects and builders. Mater. Design, 100: 102-109.

DOI: $10.1016 /$ j.matdes.2016.03.097

Gregurić, L., 2019a. 3D printed fashion-the state of the art. ALL3DP.

Gregurić, L., 2019b. 3D printing automotive applications-the latest projects. ALL 3DP.

Grimm, T., (n.d.). The real benefits of additive manufacturing.
Hager, I., A. Golonka and R. Putanowicz, 2016. 3D printing of buildings and building components as the future of sustainable construction? Proc. Eng., 151: 292-299. DOI: 10.1016/j.proeng.2016.07.357

Hedges, M. and A.B. Marin, 2012. 3D aerosol jet printing - adding electronics functionality to RP/RM. Proceedings of the DDMC Conference, (DDMC' 12), pp: 1-5.

Hemsley, B., S. Palmer, A. Kouzani, S. Adams and S. Balandin, 2019. Review informing the design of 3D food printing for people with swallowing disorders: Constructive, conceptual and empirical problems. Proceedings of the 52nd Hawaii International Conference on System Sciences, (CSS' 19), University of Hawai'i at Manoa, Honolulu, Hawaii, pp: 5735-5744. DOI: 10.24251/hicss.2019.692

Hiramatsu, M., T. Deguchi, H. Nagao and M. Hori, 2007. Aligned growth of single-walled and doublewalled carbon nanotube films by control of catalyst preparation. Japanese J. Applied Phys., 46: 191-206. DOI: $10.1143 /$ JJAP.46.L303

HRE3D+, 2018. The world's first 3D-printed titanium wheel HRE3D+. GE Additive.

Huang, R., M. Riddle, D. Graziano, J. Warren and S. Das et al., 2016. Energy and emissions saving potential of additive manufacturing: The case of lightweight aircraft components. J. Cleaner Product., 135: $1559-1570$.

DOI: 10.1016/j.jclepro.2015.04.109

Huang, S.H., P. Liu, A. Mokasdar and L. Hou, 2012. Additive manufacturing and its societal impact: A literature review. Int. J. Adv. Manuf. Technol., 67: 1191-1203. DOI: 10.1007/s00170-012-4558-5

Jacobs and P. Francis, 1992. Rapid prototyping and manufacturing: Fundamentals of stereolithography.

Jardini, A.L., M.A. Larosa, R.M. Filho, C.A.D.C. Zavaglia and L.F. Bernardes et al., 2014. Cranial reconstruction: 3D biomodel and custom-built implant created using additive manufacturing. J. Cranio-Maxillofacial Surgery, 42: 1877-1884. DOI: $10.1016 /$ j.jcms.2014.07.006

Javaid, M. and A. Haleem, 2018a. Additive manufacturing applications in medical cases: A literature based review. Alexandria J. Med., 54: 411422. DOI: 10.1016/j.ajme.2017.09.003

Javaid, M. and A. Haleem, 2018b. Additive manufacturing applications in orthopaedics: A review. J. Clin. Orthopaedics Trauma, 9: 202-206. DOI: $10.1016 /$ j.jcot.2018.04.008

Jetted Photopolymer, 2008. CustomPartNet.

Jiang, P., Z. Ji, X. Zhang, Z. Liu and X. Wang, 2018. Recent advances in direct ink writing of electronic components and functional devices. Progress Additive Manuf., 3: 65-86.

DOI: $10.1007 / \mathrm{s} 40964-017-0035-\mathrm{x}$ 
Kahlin, M., 2017. Fatigue Performance of Additive Manufactured Ti6Al4V in Aerospace Applications. 1st Edn., Linköping University Electronic Press, ISBN-13: 9789176855386, pp: 50.

Kamyshny, A. and S. Magdassi, 2019. Conductive nanomaterials for $2 \mathrm{D}$ and 3D printed flexible electronics. Chem. Society Rev., 48: 1712-1740. DOI: $10.1039 / \mathrm{c} 8 \mathrm{cs} 00738 \mathrm{a}$

Kazemian, A., X. Yuan, E. Cochran and B. Khoshnevis, 2017. Cementitious materials for construction-scale 3D printing: Laboratory testing of fresh printing mixture. Constr. Build. Mater., 145: 639-647. DOI: 10.1016/j.conbuildmat.2017.04.015

Kerns, J., 2016. How 3D printing is changing auto manufacturing. Machine Design.

Khoshnevis, B., 2004. Automated construction by contour crafting - related robotics. Autom. Constr., 13: 5-19. DOI: 10.1016/j.autcon.2003.08.012

Kidwell, J., 2014. Best practices and applications of 3D printing in the construction industry.

Kim, S., H. Seong, Y. Her and J. Chun, 2019. A study of the development and improvement of fashion products using a FDM type 3D printer. Fash. Textiles, 6: 9-9. DOI: 10.1186/s40691-018-0162-0

Kobryn, P.A., N.R. Ontko, L.P. Perkins and J.S. Tiley, 2006. Additive manufacturing of aerospace alloys for aircraft structures.

Kong, Y.L., I.A. Tamargo, H. Kim, B.N. Johnson and M.K. Gupta et al., 2014. 3D printed quantum dot light-emitting diodes. Nano Lett., 14: 7017-7023. DOI: $10.1021 / \mathrm{nl} 5033292$

Ladd, C., J.H. So, J. Muth and M.D. Dickey, 2013. 3D printing of free standing liquid metal microstructures. Adv. Mater., 25: 5081-5085. DOI: 10.1002/adma.201301400

Laminated Object Manufacturing, 2008. CustomPartNet.

Lehmhus, D., C. Aumund-Kopp, F. Petzoldt, D. Godlinski and A. Haberkorn et al., 2016. Customized smartness: A survey on links between additive manufacturing and sensor integration. Proc. Technol., 26: 284-301.

DOI: $10.1016 /$ j.protcy.2016.08.038

Lewis, J.A., 2006. Direct ink writing of 3D functional materials. Adv. Funct. Mater., 16: 2193-2204. DOI: 10.1002/adfm.200600434

Lewis, J.A., J.E. Smay, J. Stuecker and J. Cesarano, 2006. Direct ink writing of three-dimensional ceramic structures. J. Am. Ceramic Society, 89: 3599-3609. DOI: $10.1111 /$ j.1551-2916.2006.01382.x

Li, X., H. Choi and Y. Yang, (n.d.). Laser-based meso/micro rapid manufacturing system.

Liang, M., C. Shemelya, E. MacDonald, R. Wicker and H. Xin, 2015. 3-D printed microwave patch antenna via fused deposition method and ultrasonic wire mesh embedding technique. IEEE Antennas Wireless Propagat. Lett., 14: 1346-1349.

DOI: 10.1109/LAWP.2015.2405054
Lifton, V.A., G. Lifton and S. Simon, 2014. Options for additive rapid prototyping methods (3D printing) in MEMS technology. Rapid Prototyp. J., 20: 403-412. DOI: 10.1108/RPJ-04-2013-0038

Lim, S., R.A. Buswell, T.T. Le, S.A. Austin and A.G.F. Gibb et al., 2012. Developments in constructionscale additive manufacturing processes. Automat. Constr., 21: 262-268.

DOI: $10.1016 /$ j.autcon.2011.06.010

Lin, C., 2015. 3D food printing: A taste of the future. J. Food Sci. Educ., 14: 86-87. DOI: $10.1111 / 1541-4329.12061$

Lipton, J.I., M. Cutler, F. Nigl, D. Cohen and H. Lipson, 2015. Additive manufacturing for the food industry. Trends Food Sci. Technol., 43: 114-123. DOI: $10.1016 /$ j.tifs.2015.02.004

LockheadMartin, 2018. Giant satellite fuel tank sets new record for 3-D printed space parts.

Lopes, A.J., E. MacDonald and R.B. Wicker, 2012. Integrating stereolithography and direct print technologies for 3D structural electronics fabrication. Rapid Prototyp. J., 18: 129-143. DOI: $10.1108 / 13552541211212113$

Ltd, I.C.M., 2015. SLA prototypes.

Lu, B.H., H.B. Lan and H.Z. Liu, 2018. Additive manufacturing frontier: 3D printing electronics. Opto-Electronic Adv., 1: 17000401-17000410. DOI: 10.29026/oea.2018.170004

MacDonald, E. and R. Wicker, 2016. Multiprocess 3D printing for increasing component functionality. Science, 353: aaf2093-aaf2093. DOI: $10.1126 /$ science.aaf2093

Mannoor, M.S., Z. Jiang, T. James, Y.L. Kong and K.A. Malatesta et al., 2013. 3D printed bionic ears. Nano Lett., 13: 2634-2639. DOI: 10.1021/nl4007744

Manogharan, G., 2014. Hybrid manufacturing: Analysis of integrating additive and subtractive methods. North Carolina State University.

Manogharan, G., R. Wysk, O. Harrysson and R. Aman, 2015. AIMS - A metal additive-hybrid manufacturing system: System architecture and attributes. Proc. Manufact., 1: 273-286. DOI: 10.1016/j.promfg.2015.09.021

Markstedt, K., A. Mantas, I. Tournier, H. Martínez Ávila and D. Hägg et al., 2015. 3D bioprinting human chondrocytes with nanocellulose-alginate bioink for cartilage tissue engineering applications. Biomacromolecules, 16: 1489-1496.

DOI: 10.1021/acs.biomac.5b00188

Materialise, 2018. Airbus gets on board with 3D printing.

Mazumder, J. and A. Kar, 2013. Theory and Application of Laser Chemical Vapor Deposition. 1st Edn., Springer, ISBN-10: 1489914307, pp: 396.

McKenzie, J. and S. Desai, 2018. Investigating sintering mechanisms for additive manufacturing of conductive traces. Am. J. Eng. Applied Sci. 
McKenzie, J., S. Parupelli, D. Martin and S. Desai, 2017. Additive manufacturing of multiphase materials for electronics. Proceedings of the 67th Annual Conference and Expo of the Institute of Industrial Engineers, (IIE' 17), pp: 1133-1139.

Melchels, F.P.W., J. Feijen and D.W. Grijpma, 2010. A review on stereolithography and its applications in biomedical engineering. Biomaterials, 31: 61216130. DOI: 10.1016/j.biomaterials.2010.04.050

Melchels, F.P.W., M.A.N. Domingos, T.J. Klein, J. Malda and P.J. Bartolo et al., 2012. Additive manufacturing of tissues and organs. Progress Polymer Sci., 37: 1079-1104.

DOI: 10.1016/j.progpolymsci.2011.11.007

Micropen $^{\mathrm{TM}}$ manual. (n.d.).

MinistryofSupply, 2016. Introducing our 3D print-knit shop.

Musa, A., P.E, Motasem Matarneh and S. El-Ashri, 2018. The world's first 3D-printed office building in Dubai. PCI Convention.

Muth, J.T., D.M. Vogt, R.L. Truby, Y. Mengüç and D.B. Kolesky et al., 2014. Embedded 3D printing of strain sensors within highly stretchable elastomers. Adv. Mater., 26: 6307-6312.

DOI: $10.1002 / \mathrm{adma} .201400334$

NASA, 2013. Deep-space food science research improves 3D-printing capabilities. NASA SPINOFF.

NaturalMachines, 2012. Foodini real food, freshly printed.

Nechyporchuk, O., J. Yu, V.A. Nierstrasz and R. Bordes, 2017. Cellulose nanofibril-based coatings of woven cotton fabrics for improved inkjet printing with a potential in E-textile manufacturing. ACS Sustainable Chem. Eng., 5: 4793-4801. DOI: $10.1021 /$ acssuschemeng.7b00200

Nickels, L., 2015. AM and aerospace: An ideal combination. Metal Powder Rep., 70: 300-303. DOI: 10.1016/j.mprp.2015.06.005

O'Brien, F.J., 2011. Biomaterials and scaffolds for tissue engineering. Mater. Today, 14: 88-95.

DOI: 10.1016/S1369-7021(11)70058-X

O’Donnell, J., M. Kim and H.S. Yoon, 2016. A review on electromechanical devices fabricated by additive manufacturing. J. Manufact. Sci. Eng., 139: 010801-010801. DOI: 10.1115/1.4033758

ORNL, 2015. 3-D printed Shelby Cobra highlights ORNL R\&D at Detroit auto show. Department of Energy's Oak Ridge National Laboratory.

Ota, H., S. Emaminejad, Y. Gao, A. Zhao and E. Wu et al., 2016. Application of 3D printing for smart objects with embedded electronic sensors and systems. Adv. Mater. Technol., 1: 1600013-1600013.

DOI: $10.1002 / \mathrm{admt} .201600013$

Overview over 3D printing technologies: Binder Jetting, 2015. Additively.
Parupelli, S.K. and S. Desai, 2017. Understanding hybrid additive manufacturing of functional devices. Am. J. Eng. Applied Sci., 10: 264-271.

DOI: 10.3844/ajeassp.2017.264.271

Parupelli, S.K., A. Aljohani, S. Desai, S. Khanal and N. Bhattarai, 2019. Direct jet printing and characterization of calcium alginate microcapsules for biomedical applications. Proceedings of the IISE Annual Conference, (AC' 19).

Paulsen, J.A., M. Renn, K. Christenson and R. Plourde, 2012. Printing conformal electronics on 3D structures with aerosol jet technology. Proceedings of the Future of Instrumentation International Workshop Proceedings, Oct. 8-9, IEEE Xplore Press, Gatlinburg, TN, USA, pp: 47-50. DOI: 10.1109/FIIW.2012.6378343

Perkins, J., S. Desai, W. Wagner and Y. Hong, 2011. Biomanufacturing: Direct-writing of controlled release coatings for cardiovascular (Stents) applications. Proceedings of the 61th Annual IIE Conference and Expo Proceedings, (CEP' 11).

Perkins, J., Z. Xu, C. Smith, A. Roy and P.N. Kumta et al., 2015. Direct writing of polymeric coatings on magnesium alloy for tracheal stent applications. Annals Biomed. Eng., 43: 1158-1165.

DOI: $10.1007 / \mathrm{s} 10439-014-1169-3$

Perkins, J.L., S. Desai, B. Harrison and J. Sankar, 2009. Understanding release kinetics of calcium alginate microcapsules using drop on demand inkjet printing. Proceedings of the ASME International Mechanical Engineering Congress and Exposition, (ECE' 09), Lake Buena Vista, Florida USA.

Peter, Z., 2012. Why is additive manufacturing important? Modern Machine Shop.

Piner, R.D., J. Zhu, F. Xu and S. Hong, 1999. "Dip-Pen" Nanolithography.

Pique, A. and D.B. Chrisey, 2001. Direct-Write Technologies for Rapid Prototyping Applications: Sensors, Electronics and Integrated Power Sources. 1st Edn., Academic Press, ISBN-10: 0121742318, pp: 726.

Piqué, A., C.B. Arnold, R. Wartena, B. Pratap and B. Shashishekar et al., 2003. Laser direct-write of miniature sensor and microbattery systems. Riken Rev., 50: 57-62.

Pitayachaval, P., N. Sanklong and A. Thongrak, 2018. A review of $3 \mathrm{D}$ food printing technology. MATEC Web of Conf., 213: 01012-01012. DOI: $10.1051 /$ matecconf/201821301012

Rahman, M.T., A. Rahimi, S. Gupta and R. Panat, 2016. Microscale additive manufacturing and modeling of interdigitated capacitive touch sensors. Sensors Actuators, 248: 94-103.

DOI: $10.1016 /$ j.sna.2016.07.014

Rapid Prototyping, 2008. CustomPartNet. 
Riggs, B.C., A.D. Dias, N.R. Schiele, R. Cristescu and Y. Huang et al., 2011. Matrix-assisted pulsed laser methods for biofabrication. MRS Bull., 36: 1043-1050. DOI: $10.1557 / \mathrm{mrs} .2011 .276$

Rogers, J., 2014. Olli: Autonomous for all of us. Local Motors.

Ronkainen, H., (n.d.). Thermal spray direct write technology.

Rudenko, A., 2016. 3D concrete house printer.

Ružić, J., M. Vilotijević, D. Božić and K. Raić, 2012. Understanding plasma spraying process and characteristics of dc-arc plasma gun (Pj-100). Metallurgical Mater. Eng., 18: 273-282.

Saengchairat, N., T. Tran and C.K. Chua, 2017. A review: Additive manufacturing for active electronic components. Virtual Phys. Prototyp., 12: 31-46. DOI: $10.1080 / 17452759.2016 .1253181$

Salmi, M., 2013. Medical applications of additive manufacturing in surgery and dental care. Aalto University.

Saunders, S., 2018. 3D printing in automotive applications: Tooling, spare parts, race car components. 3D Print.

Seabra, M., J. Azevedo, A. Araújo, L. Reis and E. Pinto et al., 2016. Selective Laser Melting (SLM) and topology optimization for lighter aerospace componentes. Proc. Struct. Integrity, 1: 289-296. DOI: 10.1016/j.prostr.2016.02.039

Sevcik, S., 2018. 3D printing: From the automotive design studio to the factory floor. Manufacturing Global.

Shemelya, C., F. Cedillos, E. Aguilera, D. Espalin and D. Muse et al., 2015. Encapsulated copper wire and copper mesh capacitive sensing for 3-D printing applications. IEEE Sensors J., 15: 1280-1286.

DOI: 10.1109/JSEN.2014.2356973

Shemelya, C., F. Cedillos, E. Aguilera, D. Espalin and D. Muse et al., 2015. Encapsulated copper wire and copper mesh capacitive sensing for 3-D printing applications. IEEE Sensors J., 15: 1280-1286.

DOI: 10.1109/JSEN.2014.2356973

Shengjie, L., Z. Xiong, X. Wang, Y. Yan and H. Liu et al., 2009. Direct fabrication of a hybrid cell/hydrogel construct by a double-nozzle assembling technology. J. Bioactive Compatible Polymers, 24: 249-265.

DOI: $10.1177 / 0883911509104094$

Sher, D. and X. Tutó, 2015. Review of 3D food printing. Temes de Disseny.

Shi, X., S. Ma, C. Liu, C. Chen and Q. Wu et al., 2016. Performance of high layer thickness in selective laser melting of Ti6Al4V. Materials, 9: 975-975. DOI: $10.3390 / \mathrm{ma} 9120975$

Siemens and S. Zistl, 2014. Additive manufacturing: Facts and forecasts. Industry and Automation.

Singh, P. and A. Raghav, 2018. 3D food printing: A revolution in food technology. Acta Scientific Nutrit. Health, 2: 11-12.
Singh, S. and S. Ramakrishna, 2017. Biomedical applications of additive manufacturing: Present and future. Curr. Opin. Biomed. Eng., 2: 105-115. DOI: 10.1016/j.cobme.2017.05.006

Skylar-Scott, M.A., S. Gunasekaran and J.A. Lewis, 2016. Laser-assisted direct ink writing of planar and 3D metal architectures. Proc. Nat. Acad. Sci., 113: 6137-6142. DOI: 10.1073/pnas.1525131113

Sreehitha, V., 2017. Impact of 3D printing in automotive industries. Int. J. Mech. Product. Eng., 52: 2092-2320.

Standard, A., 2012. Standard terminology for additive manufacturing technologies. ASTM International F, West Conshohocken, PA.

Stereolithography (SL) Prototype Applications. (n.d.).

Stratasys, 2018. Five ways 3D printing is transforming the automotive industry five ways $3 \mathrm{D}$ printing is transforming the automotive industry.

Stucker, B., 2011. Additive manufacturing technologies: Technology introduction and business implications. Frontiers of Engineering: Reports on Leading-Edge Engineering from the 2011 Symposium.

Sultan, S. and A.P. Mathew, 2018. 3D printed scaffolds with gradient porosity based on a cellulose nanocrystal hydrogel. Nanoscale, 10: 4421-4431. DOI: $10.1039 / \mathrm{c} 7 \mathrm{nr} 08966 \mathrm{j}$

Sun, D., 2019. 3D printing in modern fashion industry. J. Textile Sci. Fash. Technol., 2: 4-7. DOI: $10.33552 /$ jtsft.2019.02.000535

Sun, J., 2010. Micropen direct-write technique for fabrication of advanced electroceramic and optical materials. Rutgers, The State University of New Jersey.

Sun, J., Z. Peng, L. Yan, J.Y.H. Fuh and G.S. Hong, 2016. 3D food printing-an innovative way of mass customization in food fabrication. Int. J. Bioprint., 2: 117-135.

Sun, J., Z. Peng, W. Zhou, J.Y.H. Fuh and G.S. Hong et al., 2015. A review on 3D printing for customized food fabrication. Proc. Manufact., 1: 308-319. DOI: 10.1016/j.promfg.2015.09.057

Sun, K., T.S. Wei, B.Y. Ahn, J.Y. Seo and S.J. Dillon et al., 2013. 3D printing of interdigitated Li-ion microbattery architectures. Adv. Mater., 25: 4539-4543. DOI: 10.1002/adma.201301036

Swack, M., 2016. New York fashion week: New movement in 3D printed fashion by three ASFOUR. Travis Fitch and Stratasys.

Tan, C., W.Y. Toh, G. Wong and L. Lin, 2018. Extrusion-based $3 \mathrm{D}$ food printing-materials and machines. Int. J. Bioprint., 4: 0-13. DOI: $10.18063 /$ ijb.v4i2.143

Tan, H.W., J. An, C.K. Chua and T. Tran, 2019. Metallic nanoparticle inks for 3D printing of electronics. Adv. Electr. Mater. DOI: 10.1002/aelm.201800831 
Thompson, B. and H.S. Yoon, 2013. Aerosol-printed strain sensor using PEDOT:PSS. IEEE Sensors J., 13: 4256-4263. DOI: 10.1109/JSEN.2013.2264482

Townsend, A., N. Senin, L. Blunt, R.K. Leach and J.S. Taylor, 2016. Surface texture metrology for metal additive manufacturing: a review. Precis. Eng., 46: 34-47. DOI: 10.1016/j.precisioneng.2016.06.001

Trevisan, F., F. Calignano, A. Aversa, G. Marchese and M. Lombardi et al., 2018. Additive manufacturing of titanium alloys in the biomedical field: Processes, properties and applications. J. Applied Biomater. Funct. Mater., 16: 57-67. DOI: $10.5301 / \mathrm{jabfm} .5000371$

Turnbull, G., J. Clarke, F. Picard, P. Riches and L. Jia et al., 2018. 3D bioactive composite scaffolds for bone tissue engineering. Bioactive Mater., 3: 278-314. DOI: $10.1016 /$ j.bioactmat.2017.10.001

Turnbull, G., J. Clarke, F. Picard, P. Riches and L. Jia et al., 2018. 3D bioactive composite scaffolds for bone tissue engineering. Bioactive Mater., 3: 278-314. DOI: 10.1016/j.bioactmat.2017.10.001

U.S. Department of Defense, Manufacturing Technologies Program, 2012. America makes.

U.S. Department of Energy, 2015. DOE quadrennial technology review 2015: Technology assessment on addtive manufacturing. Quadrennial Technology.

Udroiu, R., I.C. Braga and A. Nedelcu, 2019. Evaluating the quality surface performance of additive manufacturing systems: Methodology and a material jetting case study. Materials.

DOI: 10.3390/ma12060995

Uriondo, A., M. Esperon-Miguez and S. Perinpanayagam, 2015. The present and future of additive manufacturing in the aerospace sector: A review of important aspects. J. Aerospace Eng., 229: 2132-2147. DOI: 10.1177/0954410014568797

Valtas, A. and D. Sun, 2016. 3D printing for garments production: An exploratory study. J. Fash. Technol. Textile Eng., 04: 1-5.

DOI: $10.4172 / 2329-9568.1000139$

Ventola, C.L., 2013. Medical applications for 3D printing: Current and projected uses. P\&T, 39: 704-711. DOI: 10.1016/j.infsof.2008.09.005

Vishnu Prashant Reddy, K., I. Meera Mirzana and A. Koti Reddy, 2018. Application of additive manufacturing technology to an aerospace component for better trade-off's. Mater. Today: Proc., 5: 3895-3902.

DOI: $10.1016 /$ j.matpr.2017.11.644

Walker, K.J. and L.C. Corral, 2017. Exploring the abilities of $3 \mathrm{D}$ printing and its viability for consumption in the fashion industry. Apparel Merchandising and Product Development Undergraduate Honors Theses.
Wang, J., R.C.Y. Auyeung, H. Kim, N.A. Charipar and A. Piqué, 2010a. Three-dimensional printing of interconnects by laser direct-write of silver nanopastes. Adv. Mater., 22: 4462-4466. DOI: $10.1002 /$ adma.201001729

Wang, J., R.C.Y. Auyeung, H. Kim, N.A. Charipar and A. Piqué, 2010b. Three-dimensional printing of interconnects by laser direct-write of silver nanopastes. Adv. Mater., 22: 4462-4466.

DOI: $10.1002 /$ adma.201001729

Wimpenny, D.I., P.M. Pandey and L. Jyothish Kumar, 2016. Advances in 3D Printing and Additive Manufacturing Technologies. 1st Edn., Springer, Singapore, ISBN-10: 9811008124, pp: 186.

Winsun, 2016. Demonstrating the viability of 3D printing at construction scale. World Economic Forum.

Wu, P., J. Wang and X. Wang, 2016. A critical review of the use of 3-D printing in the construction industry. Automat. Constr., 68: 21-31.

DOI: $10.1016 / \mathrm{j}$.autcon.2016.04.005

XtreeE, 2016. XTREEE - REPORT.

XtreeE, 2017. 3D projects. from

XYZBAG, 2016. 3D printed bag.

Yamamoto, T., C. Ancely and A. Larnac, 2019. A portrait of DB.

Yang, H., W.R. Leow and X. Chen, 2018. 3D printing of flexible electronic devices. Small Meth., 2: 1700259-1700259. DOI: 10.1002/smtd.201700259

Yap, Y.L. and W.Y. Yeong, 2014. Additive manufacture of fashion and jewellery products: A mini review: This paper provides an insight into the future of 3D printing industries for fashion and jewellery products. Virtual Phys. Prototyp., 9: 195-201. DOI: 10.1080/17452759.2014.938993

Zheng, Y., Z. He, Y. Gao and J. Liu, 2013. Direct desktop printed-circuits-on-paper flexible electronics. Scientific Rep., 3: 1-7.

DOI: $10.1038 /$ srep01786

Zhu, W., X. Ma, M. Gou, D. Mei and K. Zhang et al., 2016. 3D printing of functional biomaterials for tissue engineering. Curr. Opin. Biotechnol., 40: 103-112. DOI: 10.1016/j.copbio.2016.03.014

Zhu, Z., V.G. Dhokia, A. Nassehi and S.T. Newman, 2013. A review of hybrid manufacturing processes State of the art and future perspectives. Int. J. Comput. Integrated Manufact., 26: 596-615. DOI: 10.1080/0951192X.2012.749530

Zuniga, J., D. Katsavelis, J. Peck, J. Stollberg and M. Petrykowski et al., 2015. Cyborg beast: A low-cost 3d-printed prosthetic hand for children with upperlimb differences. BMC Res. Notes, 8: 10-10. DOI: $10.1186 / \mathrm{s} 13104-015-0971-9$ 